NBER WORKING PAPER SERIES

\title{
DEFLATIONARY SHOCKS AND MONETARY RULES: AN OPEN-ECONOMY SCENARIO ANALYSIS
}

\author{
Douglas Laxton \\ Papa N'Diaye \\ Paolo Pesenti \\ Working Paper 12703 \\ http://www.nber.org/papers/w12703 \\ NATIONAL BUREAU OF ECONOMIC RESEARCH \\ 1050 Massachusetts Avenue \\ Cambridge, MA 02138 \\ November 2006
}

We thank Shin-ichi Fukuda, Takeo Hoshi, Takatoshi Ito, Andy Rose, Kazuo Ueda, Tsutomu Watanabe, Alessandro Zanello, and conference participants at the 18th Annual TRIO Conference in Tokyo for helpful suggestions. We also thank Hope Pioro, Susanna Mursula and Chris Tonetti for invaluable assistance. The views expressed in this paper are those of the authors and should not be attributed to the International Monetary Fund, IMF policy, its Executive Board, its management or any member government, the Federal Reserve Bank of New York, the Federal Reserve System, or any other institution mentioned herein or with which the authors are affiliated. The views expressed herein are those of the author(s) and do not necessarily reflect the views of the National Bureau of Economic Research.

(C) 2006 by Douglas Laxton, Papa N'Diaye, and Paolo Pesenti. All rights reserved. Short sections of text, not to exceed two paragraphs, may be quoted without explicit permission provided that full credit, including $(\odot$ notice, is given to the source. 
Deflationary Shocks and Monetary Rules: an Open-Economy Scenario Analysis

Douglas Laxton, Papa N'Diaye, and Paolo Pesenti

NBER Working Paper No. 12703

November 2006

JEL No. E17,E52,F41

\begin{abstract}
$\underline{\text { ABSTRACT }}$
The paper considers the macroeconomic transmission of demand and supply shocks in an open economy under alternative assumptions on whether the zero interest floor (ZIF) is binding. It uses a two-country general-equilibrium simulation model calibrated to the Japanese economy vis-a-vis the rest of the world. Negative demand shocks have more prolonged and startling effects on the economy when the ZIF is binding than when it is not binding. Positive supply shocks can actually extend the period of time over which the ZIF may be expected to bind. More open economies hit the ZIF for a shorter period of time, and with less harmful effects. Deflationary supply shocks have different implications according to whether they are concentrated in the tradables rather than the nontradables sector. Price-level-path targeting rules are likely to provide better guidelines for monetary policy in a deflationary environment, and have desirable properties in normal times when the ZIF is not binding.

Douglas Laxton

International Monetary Fund

700 19th Street

Washington, DC 20431

dlaxton@imf.org

Papa N'Diaye

International Monetary Fund

70019 th Street

Washington, DC 20431

pndiaye@imf.org

Paolo Pesenti

Federal Reserve Bank of New York

33 Liberty Street

New York, NY 10045

and NBER

paolo.pesenti@ny.frb.org
\end{abstract}




\section{Introduction}

In recent years, quite a few research agendas have sought to pin down the causes of deflation, mostly focusing on whether falling prices are the result of structural factors or insufficient aggregate demand. In a nutshell, structural factors such as productivity improvements in the manufacturing sector are deemed to be responsible for worldwide disinflation, while weaknesses in demand are typically assumed to be accompanied by difficulties in providing monetary policy stimulus when interest rates hit the zero interest rate floor (ZIF). Specifically, the two views above have represented recurrent themes in both the policy and academic debate on the performance of the Japanese economy over the last 15 years. ${ }^{1}$

This paper does not take a specific view about the historical contribution of demand and supply factors in the evolution of prices in Japan, nor makes any normative or policy statements on the best course of action in the near future. Rather, it makes the simple point that a country facing deflationary risks would benefit from an integrated approach involving macroeconomic policies able to respond appropriately to adverse aggregate demand shocks and deal with the consequences of eventual expansions in supply. Such framework would not only eliminate deflation in the short run, but also guard against falling into liquidity traps in the future.

Using a 2-country simulation model calibrated to the Japanese economy, the paper carries out a scenario analysis to illustrate possible difficulties in dealing with both demand and supply shocks when the ZIF is binding. It shows that the effects of negative demand shocks on the economy become more protracted and startling when the ZIF is binding than during normal times when it is not binding. It also shows that positive supply shocks (e.g. shocks that raise potential output) can extend the period of time during which the ZIF is expected to be binding, increasing the economy's vulnerability to adverse demand shocks. In addition, the paper comments on the relative benefits of alternative monetary rules in a deflationary environment, including price level targeting, inflation-targeting, and price-levelpath targeting rules. The results indicate that price-level-path targeting rules are likely to provide better guidelines for monetary policy because they are more robust in a deflationary environment, and - when appropriately designed - have desirable properties in normal times when the ZIF is not binding.

Throughout the paper we deliberately emphasize the implications of trade and financial openness on the effectiveness of monetary rules in a deflationary environment. This is not to restate the point made elsewhere (e.g. McCallum 2000 and Svensson 2001) that in an openeconomy context policymakers can escape a liquidity trap by engineering the appropriate path for the exchange rate. Rather, we show that in the face of negative demand shocks, more open economies are less vulnerable to the problems associated with the ZIF: other things being equal, they hit the ZIF for a shorter period of time, and with less harmful effects. In addition, openness can reverse the sign of the short-term response of real exchange rates to shocks. With low openness, deflation results in a very high and persistent rise in real interest rates that strengthens the home currency in real terms. In contrast, with greater openness real interest rates are not expected to increase or even remain at a high level for a long time, and the real exchange rate depreciates on impact.

Finally, the mechanism of transmission of deflationary supply shocks is significantly

\footnotetext{
${ }^{1}$ See e.g. Callen and Ostry (2003), Eggertsson and Woodford (2003, 2004), and Hunt and Laxton (2001, 2003), Hayami (2001), Hayashi and Prescott (2004), Krugman (1998a, 1998b), McCallum (2000), and Svensson (2001).
} 
affected by whether they are concentrated in the tradables or the nontradables sector. In both cases the appropriate policy response is to reduce interest rates when it is possible (either now or in the future). However, when the shock is concentrated in the nontradables sector it results in a depreciation of the real exchange rate and stronger growth in the short run, reducing the period of time over which the ZIF is binding relative to the case in which the productivity shock is concentrated in the tradables sector.

The remainder of this paper is organized as follows. Sections 2 and 3 describe the basic theoretical structure of the model and its calibration. Section 4 discusses the relative properties of price-level-path targeting rules. Section 5 then provides some illustrative scenarios to support the key arguments in the paper. The last section concludes by providing a brief discussion of possible future extensions.

\section{The structure of the model}

This section sets up a general equilibrium two-country model. ${ }^{2}$ The home country (indexed by $H$ ) is calibrated on Japanese data, while $F$ (the 'foreign' country) indexes the rest of the world. The size of the world economy is normalized to 1 , with $s^{H}$ denoting the size of the home country and $s^{F}=1-s^{H}$ the size of the rest of the world.

There is a common trend for the world economy, whose gross rate of growth between time $t$ and time $\tau$ is denoted $g_{t, \tau}$. Each period $t$ represents a quarter. All quantity variables in the model are expressed in detrended terms.

In each country, there are households, firms, and a government. Households consume a nontradable final good and supply differentiated labor inputs to firms. Firms produce final goods, tradable and nontradable intermediate goods, and provide intermediation services. The public sector consumes domestic goods and services, financed through lump-sum taxation, and manages short-term interest rates. These sectors are described in more detail below.

\subsection{Final goods}

In each country there is a continuum of symmetric firms producing two final goods, the consumption good $(A)$ and the investment good $(E)$, under perfect competition. The production function of the representative firm in the $A$ sector is:

$$
\begin{aligned}
& A_{t}^{H^{1-\frac{1}{\varepsilon_{A}^{H}}}}=\left(1-\gamma_{A}^{H}\right)^{\frac{1}{\varepsilon_{A}^{H}}} N_{A, t}^{H}{ }^{1-\frac{1}{\varepsilon_{A}^{H}}} \\
& +\gamma_{A}^{H}{ }^{\frac{1}{\varepsilon_{A}^{H}}}\left(\nu_{A}^{H}{ }^{\frac{1}{\mu_{A}^{H}}} Q_{A, t}^{H}{ }^{1-\frac{1}{\mu_{A}^{H}}}+\left(1-\nu_{A}^{H}\right)^{\frac{1}{\mu_{A}^{H}}} M_{A, t}^{{ }^{H}}{ }^{1-\frac{1}{\mu_{A}^{H}}}\right)\left(\frac{\mu_{A}^{H}}{\mu_{A}^{H}-1}\right)\left(1-\frac{1}{\varepsilon_{A}^{H}}\right)
\end{aligned}
$$

Three intermediate inputs are used in the production of the consumption good: a basket of nontradable goods $\left(N_{A}\right)$, a basket of domestic tradable goods $\left(Q_{A}\right)$, and a basket of imported goods $\left(M_{A}\right)$. The elasticity of substitution between tradables and nontradables is $\varepsilon_{A}$, and the elasticity of substitution between domestic and imported tradables is $\mu_{A}$.

\footnotetext{
${ }^{2}$ Our framework is a variant of the multi-country model presented in the Appendix of Faruqee, Laxton, Muir and Pesenti (2006), and is nested within the Global Economy Model (GEM) developed at the International Monetary Fund.
} 
The Consumer Price Index $(C P I)$ is the price of one unit of $A$. The (gross) inflation rate is defined as:

$$
\pi_{t, \tau}^{H}=\frac{C P I_{\tau}^{H}}{C P I_{t}^{H}}
$$

As a convention throughout the model, $A$ is the numeraire of the economy and all national prices are expressed in terms of domestic units of consumption, that is as ratios of $C P I$. Cost minimization determines firms' demands for intermediate inputs as:

$$
\begin{aligned}
N_{A, t}^{H} & =\left(1-\gamma_{A}^{H}\right) p_{N, t}^{H}-\varepsilon_{A}^{H} A_{t}^{H} \\
Q_{A, t}^{H} & =\gamma_{A}^{H} \nu_{A}^{H} p_{Q, t}^{H}-\mu_{A}^{H} p_{X A, t}^{H} \mu_{A}^{H}-\varepsilon_{A}^{H} A_{t}^{H} \\
M_{A, t}^{H} & =\gamma_{A}^{H}\left(1-\nu_{A}^{H}\right) p_{M A, t}^{H}-\mu_{A}^{H} p_{X A, t}^{H} \mu_{A}^{H}-\varepsilon_{A}^{H} A_{t}^{H}
\end{aligned}
$$

where $p_{N}, p_{Q}$, and $p_{M A}$ are the relative prices of the inputs in terms of consumption baskets, and $p_{X A}$ is the cost-minimizing price of the composite basket of domestic and foreign tradables:

$$
p_{X A, t}^{H}=\left(\nu_{A}^{H} p_{Q, t}^{H}{ }^{1-\mu_{A}^{H}}+\left(1-\nu_{A}^{H}\right) p_{M A, t}^{H} 1-\mu_{A}^{H}\right)^{\frac{1}{1-\mu_{A}^{H}}}
$$

The consumption good sector in the rest of the world and the investment good sector in both countries are similarly characterized, with self-explanatory changes in notation.

\subsection{Demand for intermediate goods}

There are different varieties (brands) of intermediate inputs that are produced in monopolistically competitive markets. In each country there are two kinds of intermediate goods, tradables and nontradables. Each type is defined over a continuum of mass equal to the country size. In what follows $\theta_{N}^{H}>1$ denotes the elasticity of substitution between intermediate nontradables in the baskets $N_{A}^{H}$ and $N_{E}^{H}$, while $\theta_{T}^{H}>1$ is the analogous elasticity for the baskets $Q_{A}^{H}$ and $Q_{E}^{H}$ in the home country and $M_{A}^{F}$ and $M_{E}^{F}$ in the rest of the world (similarly, $\theta_{T}^{F}>1$ is the elasticity associated with the baskets $Q_{A}^{F}, Q_{E}^{F}, M_{A}^{H}$ and $M_{E}^{H}$ ).

It is assumed that imports are subject to adjustment costs that temporarily shrink the production possibility frontier of the importing firms. This assumption allows us to model realistic dynamics of imports volumes (such as delayed and sluggish adjustment to changes in relative prices). Denoting with $M_{A}^{H, F}$ exports from the rest of the world $F$ to the $A$ sector of the home country $H$, we have:

$$
M_{A, t}^{H}=\left(1-\Gamma_{M A, t}^{H, F}\right) M_{A, t}^{H, F}
$$

The adjustment costs $\Gamma_{M A}^{H, F}$ for a representative firm $x^{H}$ are specified in terms of the firm's current import share relative to the past observed import share for the sector as a whole. These adjustments costs are zero in steady state. Specifically, we adopt the parameterization:

$$
\Gamma_{M A, t}^{H, F}\left(x^{H}\right)=\frac{\phi_{M A}^{H, F}}{2} \frac{\left[\left(M_{A, t}^{H, F}\left(x^{H}\right) / A_{t}^{H}\left(x^{H}\right)\right) /\left(M_{A, t-1}^{H, F} / A_{t-1}^{H}\right)-1\right]^{2}}{1+\left[\left(M_{A, t}^{H, F}\left(x^{H}\right) / A_{t}^{H}\left(x^{H}\right)\right) /\left(M_{A, t-1}^{H, F} / A_{t-1}^{H}\right)-1\right]^{2}}
$$

Denoting $p_{M}^{H, F}$ the home-currency price of country $F$ 's exports to $H$, cost minimization implies:

$$
p_{M A, t}^{H}\left(x^{H}\right)=\frac{p_{M, t}^{H, F}}{1-\Gamma_{M A, t}^{H, F}\left(x^{H}\right)-M_{A, t}^{H, F}\left(x^{H}\right) \Gamma_{M A, t}^{H, F}\left(x^{H}\right)}
$$


where $\Gamma_{M A}^{H, F}\left(x^{H}\right)$ is the first derivative of $\Gamma_{M A}^{H, F}\left(x^{H}\right)$ with respect to $M_{A}^{H, F}\left(x^{H}\right)$. To the extent that all firms $x^{H}$ are symmetric within the consumption sector, there will be a unique cost-minimizing import price $p_{M A}^{H}$. Similar considerations apply to the $E$ sector and the $F$ country.

\subsection{Supply of intermediate goods}

The representative nontradable intermediate good in the home country is produced with the following CES technology:

$$
N_{t}^{H}=Z_{N, t}^{H}\left(\left(1-\alpha_{K N}^{H}\right)^{\frac{1}{\xi_{N}^{H}}}\left(\ell_{N, t}^{H}\right)^{1-\frac{1}{\xi_{N}^{H}}}+\alpha_{K N}^{H} \frac{1}{\frac{1}{\xi_{N}^{H}}}\left(\left(1-s_{L C}^{H}\right) K_{N, t}^{H}\right)^{1-\frac{1}{\xi_{N}^{H}}}\right)^{\frac{\xi_{N}^{H}}{\xi_{N}^{N}-1}}
$$

Each firm uses labor $(\ell)$ and capital $(K)$ to produce $N$ units of its variety. $\xi_{N}>0$ is the elasticity of input substitution, and $Z_{N}$ is a productivity shock common to all producers of nontradables. The expression $1-s_{L C}$ denotes the share of households that own and accumulate capital and rent it to firms.

Defining as $w_{t}$ and $r_{t}$ the prices of labor and capital, the marginal cost in nontradables production is: ${ }^{3}$

$$
m c_{N, t}^{H}=\frac{1}{Z_{N, t}^{H}}\left(\left(1-\alpha_{K N}^{H}\right)\left(w_{t}^{H}\right)^{1-\xi_{N}^{H}}+\alpha_{K N}^{H}\left(r_{t}^{H}\right)^{1-\xi_{N}^{H}}\right)^{\frac{1}{1-\xi_{N}^{H}}}
$$

and the capital-labor ratio is:

$$
\left(1-s_{L C}^{H}\right) \frac{K_{N, t}^{H}}{\ell_{N, t}^{H}}=\frac{\alpha_{K N}^{H}}{1-\alpha_{K N}^{H}}\left(\frac{w_{t}^{H}}{r_{t}^{H}}\right)^{\xi_{N}^{H}}
$$

Similar considerations hold for the production of tradables. We denote by $T$ the supply of the representative intermediate tradable good. Using self-explanatory notation, we have:

$$
T_{t}^{H}=Z_{T, t}^{H}\left(\left(1-\alpha_{K T}^{H}\right)^{\frac{1}{\xi_{T}^{H}}}\left(\ell_{T, t}^{H}\right)^{1-\frac{1}{\xi_{T}^{H}}}+\alpha_{K T}^{H} \frac{1}{\xi_{T}^{H}}\left(\left(1-s_{L C}^{H}\right) K_{T, t}^{H}\right)^{1-\frac{1}{\xi_{T}^{H}}}\right)^{\frac{\xi_{T}^{H}}{\xi_{T}^{H}-1}}
$$

\subsection{Price setting in the intermediate sector}

Consider now profit maximization in the intermediate nontradables sector of the home country. The representative firm $n^{H}$ sets its nominal price by maximizing the present discounted value of real profits. Nominal rigidities are introduced in the form of adjustment costs occurring when the firm modifies its prices. Such adjustment costs are measured in terms of total profits foregone and denoted $\Gamma_{P N, t}^{H}\left\{p_{t}^{H}\left(n^{H}\right), p_{t-1}^{H}\left(n^{H}\right)\right\}$.

The price-setting problem of the firm can be characterized as:

$$
\max _{p_{t}\left(n^{H}\right)} \mathrm{E}_{t} \sum_{\tau=t}^{\infty} D_{t, \tau}^{H} \pi_{t, \tau}^{H} g_{t, \tau}\left[p_{\tau}^{H}\left(n^{H}\right)-m c_{N, \tau}^{H}\right]\left(\frac{p_{\tau}^{H}\left(n^{H}\right)}{p_{N, \tau}^{H}}\right)^{-\theta_{N}^{H}} N_{\tau}^{H}\left(1-\Gamma_{P N, \tau}^{H}\left(n^{H}\right)\right)
$$

where $D_{t, \tau}^{H}$ (with $\left.D_{t, t}^{H}=1\right)$ is the appropriate discount rate, to be defined below. As real variables are detrended and prices are deflated by $C P I$, eq. (14) includes $\pi_{t, \tau}^{H}$, the inflation

\footnotetext{
${ }^{3}$ Following the notational convention regarding prices, $m c_{t}, w_{t}$ and $r_{t}$ denote marginal costs, wages and rental rates in consumption units.
} 
rate between time $t$ and time $\tau$, and $g_{t, \tau}$, the rate of growth of the world trend between $t$ and $\tau$. Demand for the variety $n^{H}$ is a function of its relative price $p^{H}\left(n^{H}\right) / p_{N}^{H}$ (with elasticity $\theta_{N}^{H}$ ) and total consumption of nontradables, $N^{H}$.

The specific parameterization of the adjustment $\operatorname{cost} \Gamma_{P N}^{H}$ allows the model to engender realistic nominal dynamics, including inflation inertia:

$$
\Gamma_{P N, t}^{H}\left(n^{H}\right) \equiv \frac{\phi_{P N}^{H}}{2}\left(\pi_{t-1, t}^{H} \frac{p_{t}^{H}\left(n^{H}\right) / p_{t-1}^{H}\left(n^{H}\right)}{\pi_{N, t-2, t-1}^{H}}-1\right)^{2}
$$

The adjustment cost is related to changes in the price of the nontradable good $n^{H}$ relative to the past (quarterly) inflation rate observed in the nontradables sector, $\pi_{N, t-2, t-1}^{H}$. Underlying this specification is the notion that firms should not be penalized when their price changes are indexed to some (publicly observable) benchmark such as the past inflation rate for the sector as a whole. ${ }^{4}$

As firms are symmetric and charge the same equilibrium price $p^{H}\left(n^{H}\right)=p_{N}^{H}$, the first order condition can be written as:

$$
\begin{aligned}
& 0=\left(1-\Gamma_{P N, t}^{H}\right)\left[p_{N, t}^{H}\left(1-\theta_{N}^{H}\right)+\theta_{N}^{H} m c_{N, t}^{H}\right]-\left[p_{N, t}^{H}-m c_{N, t}^{H}\right] \frac{\partial \Gamma_{P N, t}^{H}}{\partial p_{N, t}^{H}} p_{N, t}^{H} \\
& -\mathrm{E}_{t} D_{t, t+1}^{H} \pi_{t, t+1}^{H} g_{t, t+1}\left[p_{N, t+1}^{H}-m c_{N, t+1}^{H}\right] \frac{N_{t+1}^{H}}{N_{t}^{H}} \frac{\partial \Gamma_{P N, t+1}^{H}}{\partial p_{N, t}^{H}} p_{N, t}^{H}
\end{aligned}
$$

Interpreting the previous equation, ${ }^{5}$ when prices are fully flexible $\left(\Gamma_{P N}^{H}=0\right)$, the optimization problem collapses to the standard markup rule:

$$
p_{N, t}^{H}=\frac{\theta_{N}^{H}}{\theta_{N}^{H}-1} m c_{N, t}^{H}
$$

where the gross markup is a negative function of the elasticity of input substitution. Deviations from markup pricing occur if firms are penalized for modifying their prices in the short term. The speed of adjustment in response to shocks depends on the trade-off between current and future expected costs, making the price-setting process forward-looking.

Similar considerations apply to the price-setting decisions of firms in the tradables sector, determining $p_{Q}^{H}, p_{Q}^{F}, p_{M}^{H, F}$ and $p_{M}^{F, H}{ }^{6}{ }^{6}$ To the extent that the home country and the rest of the world represent segmented markets, each firm needs to set two prices, one for domestic sales and the other for the export market. Without loss of generality, exports are invoiced (and prices are set) in the currency of the destination market. The adjustment costs are specified as in (15), but with possibly different parameters in the domestic market and the export market (respectively $\phi_{P Q}^{H}$ and $\phi_{P M}^{F, H}$ for the home country's firms). If the latter coefficient is relatively large, the prices of home country $H$ 's goods in the foreign markets $F$ are characterized by significant stickiness in local currency. In this case, the degree to which exchange rate fluctuations (and other shocks to marginal costs in country $H$ ) pass

\footnotetext{
${ }^{4}$ More generally, the adjustment cost could be specified relative to any variable that converges asymptotically to the steady-state inflation rate. It is worth emphasizing that the adjustment costs are related to changes in nominal prices. However, the maximization problem can be easily rewritten in terms of relative prices, as carried out in this section.

${ }^{5}$ When linearized around the steady state, eq.(16) can be written as a standard new-Keynesian Phillips curve under full indexation, or $\Delta \pi_{N, t}^{H}=\Phi m c_{N, t}^{H}+\beta \mathrm{E}_{t} \Delta \pi_{N, t+1}^{H}$, where $\Phi=\left(\theta_{N}^{H}-1\right) \theta_{N}^{H} / \phi_{P N}^{H}$.

${ }^{6}$ See Faruqee, Laxton, Muir and Pesenti (2006) for details.
} 
through onto import prices in country $F$ is rather low. If there were no nominal rigidities worldwide, export price setting would collapse to a markup rule under the law of one price, and exchange rate pass-through would be full:

$$
p_{Q, t}^{H}=\varepsilon_{t} p_{M, t}^{F, H}=\frac{\theta_{T}^{H}}{\theta_{T}^{H}-1} m c_{T, t}^{H}
$$

where $\varepsilon$ is the CPI-based real exchange rate (an increase in $\varepsilon$ representing a real depreciation for the home country $H$ ). By choosing an appropriate parameterization for $\phi_{P M}$ in both countries, it is possible to reproduce realistic values for the elasticity of exchange rate passthrough in the short run. In the long run, however, pass-through is full and the law of one price holds in both markets.

\subsection{Consumer preferences}

In each country there is a continuum of households. Some households have access to capital markets, and others do not. Those who don't have access to capital markets finance their consumption exclusively through their labor income. This type of consumers is referred to as 'non-Ricardian' or 'liquidity-constrained', and indexed with $L C$. In the home country, they represent a share $s_{L C}^{H}$ of domestic households. Those who have access to capital markets are referred to as 'Ricardian' or 'forward-looking', and indexed with $F L$. In the home country, they represent a share $\left(1-s_{L C}^{H}\right)$ of domestic households.

The specification of households' preferences uses the Greenwood, Hercowitz and Huffman (1988) (GHH) utility function, adjusted for habit formation and preference shocks. Denoting with $\mathcal{W}_{t}^{H}\left(j^{H}\right)$ the lifetime expected utility of the representative household $j^{H}$ in the home country, we have:

$$
\mathcal{W}_{t}^{H}\left(j^{H}\right) \equiv \mathrm{E}_{t} \sum_{\tau=t}^{\infty} \beta_{t, \tau}^{H} g_{t, \tau}^{1-\sigma} u_{\tau}^{H}\left(C_{\tau}^{H}\left(j^{H}\right), \ell_{\tau}^{H}\left(j^{H}\right)\right)
$$

where the instantaneous felicity is a function of consumption $C$ and labor effort $\ell$ :

$$
\begin{aligned}
& u_{t}^{H}\left(j^{H}\right)=Z_{U, t}^{H}\left(1-\frac{b_{c}^{H}}{g_{t-1, t}}\right)\left(\frac{1-b_{\ell}^{H}}{1-\sigma}\right) \\
& *\left[\frac{C_{t}^{H}\left(j^{H}\right)-b_{c}^{H} C_{j^{H}, t-1}^{H} / g_{t-1, t}}{1-b_{c}^{H} / g_{t-1, t}}-\frac{Z_{V, t}^{H}}{1+\zeta^{H}}\left(\frac{\ell_{t}^{H}\left(j^{H}\right)-b_{\ell}^{H} \ell_{j, t-1}^{H}}{1-b_{\ell}^{H}}\right)^{1+\zeta^{H}}\right]^{1-\sigma}
\end{aligned}
$$

In the expressions above $\beta_{t, \tau}^{H}$ is the discount rate between time $t$ and time $\tau$, possibly different across countries. The disutility of labor effort is assumed to increase with the global trend (hence the term $g_{t, \tau}^{1-\sigma}$ in 19). ${ }^{7}$ The parameter $\sigma$ in (19) and (20) is the reciprocal of the elasticity of intertemporal substitution. The parameter $\zeta$ which affects the curvature of labor disutility is the reciprocal of the Frisch elasticity.

There is habit persistence in consumption with coefficient $0<b_{c}<1$. The term $C_{j^{H}, t-1}$ in (20) is past per-capita consumption of household $j^{H}$ 's peers, (i.e., either forward-looking or liquidity-constrained agents). Similarly, there is habit persistence in leisure with coefficient $0<b_{\ell}<1 .{ }^{8}$ The terms $Z_{U}$ and $Z_{V}$ are preferences shocks. Households' preferences

\footnotetext{
${ }^{7}$ Appropriate restrictions are imposed to ensure that utility is bounded. In particular, in steady state we have $\beta_{S S} g_{S S}^{1-\sigma}<1$ in all countries.

${ }^{8}$ The instantaneous felicity is normalized such that in a steady state $U, U_{C}$ and $U_{\ell}$ can all be written as constant $* f(C, \ell)$, where $f$ is some function of steady-state consumption and labor effort, independent of the habit persistence coefficients.
} 
are therefore symmetric within their respective categories but, because of different reference groups in habit formation, they are not symmetric across categories.

\subsection{Ricardian households}

Ricardian households in the home country hold two nominal bonds, denominated in domestic and foreign currency, respectively. The domestic bond is in zero net supply in the home country, and only the foreign-currency denominated bond is traded internationally. $B_{t}^{H}\left(j_{F L}^{H}\right)$ denotes the holdings of the domestic bond by households $j_{F L}^{H}$, expressed in terms of domestic consumption units, and $B_{F, t}^{H}\left(j_{F L}^{H}\right)$ that of international bond, expressed in terms of foreign consumption units. The nominal returns on these bonds are denoted $i_{t}^{H}$ and $i_{t}^{F}$. They are paid at the beginning of period $t+1$ and known at time $t$. The two rates are directly controlled by their respective national governments.

Home agents who take a position in the international bond market must deal with financial intermediaries who charge a transaction fee $\Gamma_{B F}^{H}$ on sales/purchases of the international bond. ${ }^{9}$ The net financial wealth of the home country, expressed in local consumption baskets, is therefore:

$$
F_{t}^{H} \equiv\left(1+i_{t-1}^{F}\right)\left[1-\Gamma_{B F, t-1}^{H}\right] \frac{\varepsilon_{t} B_{F, t-1}^{H}}{\pi_{t-1, t}^{F} g_{t-1, t}}
$$

The financial friction is introduced to guarantee that international net asset positions follow a stationary process and the economies converge asymptotically to a well-defined steady state. Specifically, we adopt the following functional form:

$$
1-\Gamma_{B F, t}^{H}=\left(1-\phi_{B 1}^{H} \frac{\exp \left\{\phi_{B 2}^{H}\left(\varepsilon_{t}\left(1-s_{L C, t}^{H}\right) B_{F, t}^{H} / G D P_{t}^{H}-b_{F, R A T, S S}^{H}\right)\right\}-1}{\exp \left\{\phi_{B 2}^{H}\left(\varepsilon_{t}\left(1-s_{L C, t}^{H}\right) B_{F, t}^{H} / G D P_{t}^{H}-b_{F, R A T, S S}^{H}\right)\right\}+1}\right) \frac{\beta_{t-1, t}^{F}}{\beta_{t-1, t}^{H}}
$$

The term $b_{F, R A T, S S}^{H}$ is the steady-state net asset position of the home country expressed as a ratio of $G D P^{H} .{ }^{10}$ This variable measures the degree of international exposure that financial intermediaries consider appropriate, based on their long-term assessment of the economy. In our simulation we set $b_{F, R A T, S S}^{H}=0$, as alternative parameterizations leave our results virtually unchanged.

To understand the role played by $\Gamma_{B F}^{H}$, suppose that $\beta^{F}=\beta^{H}$. In this case, when the net asset position of the country is equal to its steady-state level of zero, it must be the case that $\Gamma_{B F}^{H}=0$ and the return on the international bond is equal to $1+i^{F}$. If instead home residents are net creditors worldwide, $\Gamma_{B F}^{H}$ rises above zero, implying that the country's households lose an increasing fraction of their international bond returns to financial intermediaries. By the same token, if the home country is a net debtor worldwide $\Gamma_{B F}^{H}$ becomes negative (with a floor of $-\phi_{B 1}$ ), implying that households pay an increasing intermediation premium on their international debt. ${ }^{11}$ When rates of time preference diverge across countries and $\beta^{H} \neq \beta^{F}$, the transaction cost is appropriately modified to account for asymmetries in real interest rates across countries. An appropriate parameterization allows the model to generate realistic dynamics for net asset positions and current account.

\footnotetext{
${ }^{9}$ In our model it is assumed that all intermediation firms are owned by the country's residents, and that their revenue is rebated to domestic households in a lump-sum fashion.

${ }^{10}$ The concept of GDP in our model will be discussed below.

${ }^{11}$ More generally, the term $b_{F, R A T, S S}^{H}$ could be different from zero. The above considerations would still be valid after reinterpreting the concepts of 'net creditor' or 'net borrower' in terms of deviations from the steady-state level.
} 
Ricardian households accumulate physical capital which they rent to domestic firms at the rate $r$. The law of motion of capital is:

$$
K_{t}^{H} g_{t-1, t}=\left(1-\delta^{H}\right) K_{t-1}^{H}+\Gamma_{I, t-1}^{H} K_{t-1}^{H} \quad 0<\delta \leq 1
$$

where $\delta^{H}$ is the country-specific depreciation rate of capital. Capital accumulation is subject to adjustment costs $\Gamma_{I}$. The specific functional form we adopt is quadratic and encompasses inertia in investment:

$$
\Gamma_{I, t}^{H} \equiv \frac{I_{t}^{H}}{K_{t}^{H}}\left(1+Z_{I, t}^{H}\right)-\frac{\phi_{I 1}^{H}}{2}\left(\frac{I_{t}^{H}}{K_{t}^{H}}-\left(\delta^{H}+g_{S S}-1\right)\right)^{2}-\frac{\phi_{I 2}^{H}}{2}\left(\frac{I_{t}^{H}}{K_{t}^{H}}-\frac{I_{t-1}^{H}}{K_{t-1}^{H}}\right)^{2}
$$

where $\phi_{I 1}, \phi_{I 2} \geq 0, Z_{I}$ is a shock to investment demand and $g_{S S}$ is the steady-state growth rate.

Labor inputs are differentiated and come in different varieties (skills). They are defined over a continuum of mass equal to the country size. In what follows $\psi^{H}>1$ is the elasticity of substitution among labor inputs in the home country. Each household is the monopolistic supplier of a specific labor input and sets the nominal wage for its specific labor variety. The representative Ricardian household $j_{F L}^{H}$ faces a downward-sloping demand for its labor input as a function of its relative wage $w_{F L}^{H} / w^{H}$ :

$$
\ell_{F L, t}^{H}=\left(1-s_{L C}^{H}\right)\left(w_{F L, t}^{H} / w_{t}^{H}\right)^{-\psi^{H}} \ell_{t}^{H}
$$

where $\ell^{H}$ is aggregate labor effort in the home country. There is sluggish wage adjustment due to resource costs that are measured in terms of the total wage bill. The adjustment cost is specified as the analog of (15) above, with parameter $\phi_{W F L}^{H}$.

Ricardian households own all domestic firms and there is no international trade in claims on firms' profits. All profits accruing to shareholders, together with all revenue from nominal and real adjustment as well as revenue from financial intermediation are distributed in a lump-sum way to all Ricardian households. In addition, all net taxes paid to the government are lump-sum.

The representative Ricardian household chooses bond holdings, capital and consumption paths, and sets its nominal wage to maximize its expected lifetime utility (19) subject to its budget constraint. The stochastic discount rate $D_{t, \tau}^{H}$ is defined as:

$$
D_{t, \tau}^{H} \equiv \beta_{t, \tau}^{H} g_{t, \tau}^{1-\sigma} \frac{\partial u_{F L, \tau}^{H} / \partial C_{F L, \tau}^{H}}{\partial u_{F L, t}^{H} / \partial C_{F L, t}^{H}} \frac{1}{\pi_{t, \tau}^{H}} \frac{1}{g_{t, \tau}}
$$

Accounting for the above expressions, the bond-pricing equations are, respectively:

$$
\begin{aligned}
& 1=\left(1+i_{t}^{H}\right) \mathrm{E}_{t} D_{t, t+1}^{H} \\
& 1=\left(1+i_{t}^{F}\right)\left(1-\Gamma_{B F, t}^{H}\right) \mathrm{E}_{t}\left(D_{t, t+1}^{H} \Delta_{t, t+1}^{H}\right)
\end{aligned}
$$

where $\Delta^{H}$ denotes the rate of nominal exchange rate depreciation in the home country, or:

$$
\Delta_{t, \tau}^{H}=\frac{\varepsilon_{\tau}}{\varepsilon_{t}} \frac{\pi_{t, \tau}^{H}}{\pi_{t, \tau}^{F}}
$$

In a non-stochastic steady state (27) implies $\left(1+i_{S S}^{H}\right) / \pi_{S S}^{H}=g_{S S}^{\sigma} / \beta_{S S}^{H}$, where $\pi_{S S}^{H}$ is the (gross steady-state quarterly) inflation rate, $\left(1+i_{S S}^{H}\right) / \pi_{S S}^{H}$ is the real interest rate, $g_{S S}^{H}$ 
is the (gross steady-state quarterly) rate of growth of the world economy, $1 / \beta_{S S}^{H}$ is the rate of time preference, and $g_{S S}^{\sigma} / \beta_{S S}^{H}$ is the "natural' rate of the economy. ${ }^{12}$ In a nonstochastic steady state the interest differential $\left(1+i_{S S}^{H}\right) /\left[\left(1+i_{S S}^{F}\right)\left(1-\Gamma_{B F, S S}^{H}\right)\right]$ is equal to the steady-state nominal depreciation rate of the home currency, and relative purchasing power parity holds.

Optimal capital accumulation is determined according to:

$$
\begin{aligned}
& \frac{p_{E, t}^{H}}{\partial \Gamma_{I, t}^{H} / \partial\left(I_{t}^{H} / K_{t}^{H}\right)} \mathrm{E}_{t} g_{t, t+1}=\mathrm{E}_{t}\left\{D _ { t , t + 1 } ^ { H } \pi _ { t , t + 1 } ^ { H } g _ { t , t + 1 } \left(r_{t+1}^{H}\right.\right. \\
& \left.\left.+\frac{p_{E, t+1}^{H}}{\partial \Gamma_{I, t+1}^{H} / \partial\left(I_{t+1}^{H} / K_{t+1}^{H}\right)}\left[1-\delta^{H}+\Gamma_{I, t+1}^{H}-\frac{\partial \Gamma_{I, t+1}^{H}}{\partial\left(I_{t+1}^{H} / K_{t+1}^{H}\right)} \frac{I_{t+1}^{H}}{K_{t+1}^{H}}\right]\right)\right\}
\end{aligned}
$$

where $p_{E}^{H} / \partial \Gamma_{I}^{H} / \partial\left(I^{H} / K^{H}\right)$ can be interpreted as Tobin's Q. In a non-stochastic steady state $1+r_{S S}^{H} / p_{E, S S}^{H}$ is equal to the sum of the natural real rate $g_{S S}^{\sigma} / \beta_{S S}^{H}$ and the rate of capital depreciation $\delta .{ }^{13}$

Finally, the first order condition with respect to the nominal wage yields an expression similar to (16) above. In a non-stochastic steady state the real wage of the Ricardian household $w_{F L}^{H}$ is equal to the marginal rate of substitution between consumption and leisure, $-\left(\partial u_{F L, t}^{H} / \partial \ell_{F L, t}^{H}\right) /\left(\partial u_{F L, t}^{H} / \partial C_{F L, t}^{H}\right)$, augmented by the markup $\psi^{H} /\left(\psi^{H}-1\right)$ which reflects monopoly power in the labor market.

The rest of the world is similarly characterized. However, there are no intermediation costs in entering the international bond market for the Ricardian households of the $F$ country.

\subsection{Liquidity-constrained households}

Liquidity-constrained households have no access to capital markets. However, they face a downward-sloping demand for their labor inputs as a function of their relative wage:

$$
\ell_{L C, t}^{H}=s_{L C}^{H}\left(w_{L C, t}^{H} / w_{t}^{H}\right)^{-\psi^{H}} \ell_{t}^{H}
$$

As in the case of Ricardian households, they can set optimally their wages using their market power, subject to adjustment costs with parameter $\phi_{W L C}^{H}$. It is assumed that redistribution policies provide to these households the income losses associated with wage adjustment, implying that their consumption level is:

$$
C_{F L, t}^{H}=w_{L C, t}^{H} \ell_{L C, t}^{H}
$$

and the optimal wage setting process is:

$$
-\frac{\partial u_{L C, t}^{H} / \partial \ell_{L C, t}^{H}}{\partial u_{L C, t}^{H} / \partial C_{L C, t}^{H}} \frac{\psi^{H}}{w_{L C, t}^{H}}=\left(\psi^{H}-1\right)\left(1-\Gamma_{W L C, t}^{H}\right)+\frac{\partial \Gamma_{W L C, t}^{H}}{\partial w_{L C, t}} w_{L C, t}^{H}
$$

\footnotetext{
${ }^{12}$ International differences in natural rates can arise from asymmetric rates of time preference. They are accounted for in the definition of $\Gamma_{B}$ in $(22)$.

${ }^{13}$ The expectation operator on the left hand side of $(30)$ is needed as shocks to the trend $g_{t, t+1}$ are not part of the information set at time $t$. This is because variables are expressed as deviations from the current trend. An alternative specification which expresses variables as deviations from the lagged trend would make little difference.
} 
Finally, the wage rate for the whole economy is:

$$
w_{t}^{H}{ }^{1-\psi^{H}}=s_{L C}^{H} w_{L C}^{H 1-\psi^{H}}+\left(1-s_{L C, t}^{H}\right) w_{F L}^{H 1-\psi^{H}}
$$

Similar considerations hold in the $F$ country.

\subsection{Government}

Public spending is limited to nontradable goods, both final and intermediate. In per-capita terms, $G_{C}^{H}$ is government consumption, $G_{I}^{H}$ is government investment, and $G_{N}^{H}$ denotes public purchases of intermediate nontradables. Government spending is financed through lump-sum taxation

The governments control the short-term rates $i_{t}^{H}$ and $i_{t}^{F}$. In the home country, monetary policy encompasses both inflation and price level targeting and is specified in terms of an annualized interest rate rule of the form:

$$
\left(1+i_{t}^{H}\right)^{4}=\left(1+i_{t}^{\text {neut }} H\right)^{4}+\omega_{\pi}^{H}\left(\pi_{t-4, t}^{H}-\Pi_{T A R}^{H}{ }_{t-4, t}\right)+\omega_{P}^{H} \ln \left(\frac{C P I_{t}^{H}}{C P I_{T A R, t}^{H}}\right)
$$

The current interest rate $i_{t}$ is a function of the current 'neutral' rate $i_{t}^{\text {neut }}$, defined as the quarterly nominal interest rate that would prevail if the real interest rate were equal to the natural rate and inflation were equal to its target:

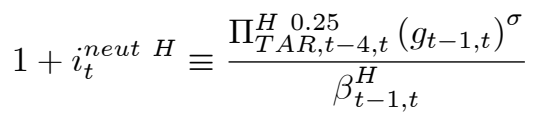

The current rate can differ from neutral to account for the gap between current year-on-year inflation $\left(\pi_{t-4, t}^{H}\right)$ and its target $\left(\Pi_{T A R t-4, t}^{H}\right)$, as well as the gap between the current price level $C P I_{t}^{H}$ and its target $C P I_{T A R, t}^{H}$. The latter is defined according to:

$$
\Pi_{T A R t, \tau}^{H}=\frac{C P I_{T A R, \tau}^{H}}{C P I_{T A R, t}^{H}}
$$

All nominal prices are normalized at the initial time $t=0$ such that $C P I_{0}=C P I_{T A R, 0}=1$. We refer to the expression (35) as a Price-Level-Path Targeting (PLPT) rule when the target rate of inflation is positive and a Price-Level Targeting (PLT) rule when the target rate of inflation is zero.

In general, the rule (35) could be modified to include policy responses to a set of other variables (such as output gap, output growth rate, exchange rate, current account etc.) expressed as deviations from their targets. In a steady state when all targets are reached it must be the case that the real interest rate is equal to the 'natural' rate of the economy, a function of the long-term growth rate and the discount rate:

$$
1+i_{S S}^{H}=1+i_{S S}^{\text {neut } H}=\frac{\Pi_{S S}^{H}{ }^{0.25} g_{S S}^{\sigma}}{\beta_{S S}^{H}}=\frac{\pi_{S S} g_{S S}^{\sigma}}{\beta_{S S}} .
$$

In the rest of the world monetary policy is similarly specified, but the interest rate rule is assumed to only respond to deviations of inflation from the target. 


\subsection{Market clearing}

The model is closed by imposing the following resource constraints and market clearing conditions.

The resource constraint in the nontradables sector is:

$$
N_{t}^{H}=N_{A, t}^{H}+N_{E, t}^{H}+G_{N, t}^{H}
$$

The resource constraint in the tradables sector in the home country is:

$$
T_{t}^{H}=Q_{A, t}^{H}+Q_{E, t}^{H}+\frac{s^{F}}{s^{H}}\left(M_{A, t}^{F, H}+M_{E, t}^{F, H}\right)
$$

and similarly, in the rest of the world:

$$
T_{t}^{F}=Q_{A, t}^{F}+Q_{E, t}^{F}+\frac{s^{H}}{s^{F}}\left(M_{A, t}^{H, F}+M_{E, t}^{H, F}\right)
$$

The resource constraints in the labor and capital markets are:

$$
\begin{aligned}
K_{t}^{H} & =K_{T, t}^{H}+K_{N, t}^{H} \\
\ell_{t}^{H} & =\ell_{N, t}^{H}+\ell_{T, t}^{H}
\end{aligned}
$$

The final good $A$ can be used for private (by both liquidity-constrained and forwardlooking households) or public consumption:

$$
A_{t}^{H}=C_{t}^{H}+G_{C, t}^{H}=s_{L C, t}^{H} C_{L C, t}^{H}+\left(1-s_{L C, t}^{H}\right) C_{F L, t}^{H}+G_{C, t}^{H}
$$

and similarly for the investment good $E$ :

$$
E_{t}^{H}=\left(1-s_{L C, t}^{H}\right) I_{t}^{H}+G_{I, t}^{H}
$$

All profits and intermediation revenue accrue to Ricardian households. Market clearing in the asset market requires:

$$
\begin{aligned}
& B_{t}^{H}=0 \\
& s^{H}\left(1-s_{L C, t}^{H}\right) B_{F, t}^{H}+\left(1-s^{H}\right)\left(1-s_{L C, t}^{F}\right) B_{F}^{F}=0
\end{aligned}
$$

Finally, the law of motion for financial wealth is derived by aggregating agents' budget constraints:

$$
\begin{aligned}
& \mathrm{E}_{t} D_{t, t+1}^{H} \pi_{t, t+1}^{H} g_{t, t+1}\left(1-s_{L C}^{H}\right) F_{t+1}^{H}=\left(1-s_{L C}^{H}\right) F_{t}^{H}+\Gamma_{B F, t-1}^{H} \frac{\left(1+i_{t-1}^{F}\right) \varepsilon_{t}\left(1-s_{L C}^{H}\right) B_{F, t-1}^{H}}{\pi_{t-1, t}^{F} g_{t-1, t}} \\
& +p_{N, t}^{H} N_{t}^{H}+p_{T, t}^{H} T_{t}^{H}-C_{t}^{H}-p_{E, t}^{H} I_{t}^{H}-G_{t}^{H}
\end{aligned}
$$

where the total value of tradables is defined as:

$$
p_{T, t}^{H} T_{t}^{H} \equiv p_{Q, t}^{H}\left(Q_{A, t}^{H}+Q_{E, t}^{H}\right)+\frac{s^{F}}{s^{H}} \varepsilon p_{M, t}^{F, H}\left(M_{A, t}^{F, H}+M_{E, t}^{F, H}\right)
$$

and total government spending is:

$$
G_{t}^{H}=G_{C, t}^{H}+p_{E, t}^{H} G_{I, t}^{H}+p_{N, t}^{H} G_{N, t}^{H}
$$




\subsection{Measuring output and current account}

Expression (48) can be written as:

$$
C B A L_{t}^{H}=\left(1-s_{L C}^{H}\right) \varepsilon_{t}\left(B_{F, t}^{H}-\frac{B_{F, t-1}^{H}}{\pi_{t-1, t}^{F} g_{t-1, t}}\right)=\left(1-s_{L C}^{H}\right) \frac{i_{t-1}^{F} \varepsilon_{t} B_{F, t-1}^{H}}{\pi_{t-1, t}^{F} g_{t-1, t}}+T B A L_{t}^{H}
$$

The left hand side of (51) is country $H$ 's current account, the first term on the right hand side are net factor payments from the rest of the world to country $H$ and $T B A L$ is the trade balance. The latter can be thought of as:

$$
T B A L_{t}^{H}=E X_{t}^{H}-I M_{t}^{H}
$$

where total exports $E X$ are:

$$
E X_{t}^{H}=p_{T, t}^{H} T_{t}^{H}-p_{Q, t}^{H}\left(Q_{A, t}^{H}+Q_{E, t}^{H}\right)
$$

and total imports $I M$ are:

$$
I M_{t}^{H}=p_{M, t}^{H, F}\left(M_{A, t}^{H, F}+M_{E, t}^{H, F}\right)
$$

Finally, we define the model-based gross domestic product (in units of consumption) as:

$$
G D P_{t}^{H}=A_{t}^{H}+p_{E, t}^{H} E_{t}^{H}+p_{N, t}^{H} G_{N, t}^{H}+E X_{t}^{H}-I M_{t}^{H}
$$

\section{Model calibration}

Tables 1-5 report the parameterization of the home and foreign blocks in the simulations. The steady-state ratios have been set to match actual national accounts data and the key behavioral parameters have been chosen using information from the existing literature-see Batini, N'Diaye, and Rebucci (2005)-as well as empirical evidence gathered in previous work using the International Monetary Fund's Global Economy Model (GEM).

The home country, Japan, accounts for $11 \frac{1}{2}$ percent of the world and the remaining countries $F$ account for the remaining $88 \frac{1}{2}$ percent (Table 1 ). The steady state consumptionto-GDP ratio is lower in Japan than in the rest of the world ( 57 percent compared with 65 percent), but investment, government expenditure, exports, and imports, are higher in Japan than in the rest of the world. There are also differences in the key parameters that characterize consumption, production, and the dynamics of key macroeconomic variables.

With regard to consumption behavior (Table 2), the two regions have similar shares of consumers facing liquidity constraints (40 percent). At the same time, it is assumed that consumers in Japan are more patient than those in the rest of the world with a rate of time preference - i.e. the inverse of the subjective discount factor - of 1.43 compared with 2.59. The intertemporal elasticity of substitution $1 / \sigma$ is assumed to be identical across regions and consumers (liquidity-constrained and forward looking) and set to 5. Combining these three parameters with a steady-state balanced-growth trend rate $g_{S S}$ for the world economy of 2 percent (in annualized terms) implies a real interest rate of 1.83 percent in Japan and 3 percent for the world economy. In the case of Japan, this level of real interest rate is consistent with the average real long-term interest rate during 1995-1999. For the remaining countries, the lower bound of the typical calibration of 3-4 percent for the real interest rate has been used (Christiano, Eichenbaum, and Evans (1999)). 
The parameter of habit persistence in consumption, $b_{c}$, is set at a high value of 0.91 for both regions, consistent with values used in previous studies such as Bayoumi, Laxton, and Pesenti (2004). This assumption, together with the high intertemporal elasticity of substitution, generates realistic short-run paths for the dynamics of consumption and the hump-shaped response to changes in interest rates. More conservative values used in sensitivity analysis do not alter significantly the long-term properties of the model. ${ }^{14} \mathrm{We}$ calibrate the Frisch elasticity at 0.4, slightly higher than the 0.05-0.33 range of estimates obtained using micro data but well below benchmark values in macroeconomic models, and set the habit persistence in leisure, $b_{\ell}$, at 0.75 for both regions and types of consumers.

As regards production, it is assumed that the tradable sector is more capital intensive than the non-tradable sector in both regions. The elasticity of substitution between labor and capital $\xi$ is set at 0.75 in both the tradable sector and the non-tradable sector for both regions. Such a value proved useful in helping to reduce the sensitivity of capital to changes in interest rates. The bias toward the use of capital $\alpha_{K}$ has been set to replicate the actual average investment-to-GDP ratio. The depreciation rate $\delta$ is assumed to be 2 percent per quarter (8 percent a year).

The markups on tradable and non-tradables, which reflect the pricing power of firms under monopolistic competition as a function of the elasticities $\theta$ and $\psi$, are set using estimates from Martins, Scarpetta, and Pilat (1996) for Japan and the rest of the world (Table 3). These estimates indicate lower markups over marginal costs for both the tradable sector and the non-tradable sector in the case of the rest of world compared with Japan, suggesting a lower degree of competition in the goods market of the latter region. For the labor market however, it is assumed that agents have the same pricing power in both regions with a real wage markup of 20 percent.

With regards to the dynamics of the key macro aggregates (Table 4), it is largely dependent upon the assumptions made on the adjustment cost parameters associated to the nominal and real aggregates. In particular, the adjustment cost parameter for wages is set at 400 , broadly in line with a four-quarter contract under Calvo-style pricing. The adjustment cost parameter on prices is also set at 400 , consistent with a sacrifice ratio of 2.1 . The adjustment cost on import prices is set at 3200 , which implies a short-run pass-through of the exchange rate of about 0.5 . The adjustment cost on import volumes is set at 0.95 to mimic a slow response of import volumes to changes in demand and relative prices. The transactions costs parameters in the bond market are chosen so as to ensure a slow reversion of the net asset position between the two regions to its steady-state value.

Finally, as regards the parameterization of the monetary reaction functions (Table 5), this is such that both regions are committed to price stability with, however, marked differences in the policy rules. As remarked above, it is assumed that the home country follows a PLPT rule. The purpose of this assumption is to simulate the effects that a policy commitment to achieve a specified target path for the price level would have on the macroeconomy of a country facing disinflationary risks, consistent with the suggestion of several studies that a PLPT rule is an effective means to mitigate the implications of the zero bound on nominal interest rates. ${ }^{15}$ More specifically, the baseline PLPT rule uses a coefficient of 2 on the

\footnotetext{
${ }^{14}$ Because of the specification of the utility function (20) in our model, the value of $\sigma$ plays a lesser role in determining the properties of the steady-state allocation than under alternative parameterizations (e.g. additive separability or Cobb-Douglas). However, the choice of $\sigma$ - interacted with habit persistence $b_{C}$ - critically affects the dynamic properties of the model.

${ }^{15}$ See e.g. Reifschneider and Williams (1999), Hunt and Laxton (2001), and Eggertson and Woodford (2003).
} 
current quarter gap between the year-on-year inflation and its target and a coefficient of 0.5 on the current quarter gap between the price level and its target. Under this policy rule the price level would only be expected to return very gradually back to the target path and in a manner that pays sufficient consideration for its implications for the real economy. However, for illustrative purposes we will also show a scenario where we assume a very aggressive policy response that attempts to bring the price level back to the target much faster (by assuming the weight on the price level gap is 2.5 instead of 0.5 ).

The interest rate rule for the rest of the world uses a coefficient of 2 on the current quarter gap between the year-on-year inflation and its target. The year-on-year inflation target is set at 0.5 percent for Japan, which is broadly in line with the average inflation rate during 1995-1999, and 2.5 percent for the rest of the world.

\section{PLPT rules versus other rules}

It is well known that standard inflation-targeting rules that only respond to actual or expected inflation developments - such as the Taylor (1993) rule - may give rise to either indeterminacy or instability in the presence of the ZIF. A number of solutions have been suggested to overcome stability problems while guarding against the risks of deflation. Hybrid rules where the central bank commits to adjusting a short-term interest rate in response to both inflation and deviations between the price level and a fixed price level path have received increasing attention in the literature and policy debate. ${ }^{16}$ The next section shows that targeting an upward-sloping price level path (PLPT) not only helps eliminate a deflationary spiral once the ZIF has been hit, but it can also reduce the risks of hitting the ZIF itself.

Some skepticism however has been expressed on the effectiveness, and even the desirability, of such rules. It is sometimes argued that, in the presence of structural inflation persistence, PLT and PLPT rules can result in excessive instability of the real activity, and might push an economy into deflation in circumstances where the actual price level is significantly higher than the target. Another criticism is that PLPT rules are successful in models because they exploit expectational channels, but in the real world may be less credible than pure inflation targeting (IT) rules. In light of this debate, before turning to our main results we find it useful to use our analytical apparatus to illustrate why we consider these concerns to be unwarranted.

Let's first consider the case in which the current price level is severely misaligned relative to the target. Specifically, Figure 1 considers a scenario where the initial price level is 5 percent above a constant price level target, and the central bank pursues an overly aggressive policy of returning the price level back to target within 2 years. ${ }^{17}$ In terms of our model, the central bank adopts a PLT rule with a high weight of 2.5 on the price level gap in the monetary reaction function. We emphasize that this scenario is analyzed merely to visualize the concerns above, according to which such a policy conduct would push the economy into a deflationary spiral.

\footnotetext{
${ }^{16}$ See among others Benhabib, Schmitt-Grohe, and Uribe (2002), Buiter and Panigirtzoglou (2000), Eggertsson and Woodford (2003, 2004), Hunt and Laxton (2001, 2003), Krugman (1998a, 1998b), McCallum (2000), Svensson (2001).

${ }^{17}$ We assume that all other variables are initially at their steady-state values, so that we can focus specifically on a situation where the price level is initially misaligned relative to the target without additional deviations from the long-run equilibrium.
} 
Indeed, in this example interest rates rise to double digits in the short run and then decline over time as the price level falls toward the target. In the presence of structural inflation persistence such a policy eventually requires interest rates to fall significantly below the neutral rate (the dashed line in the bottom right chart of Figure 1). But, as the neutral rate is quite low because of the zero slope of the price-level path target, there is a substantial chance that the economy hits the ZIF, with negative repercussions on real activity. In fact, in our scenario the economy hits the ZIF in the second and third year of the simulation, resulting in a large recession. It is important to understand that there are two forces at work here that result in the economy hitting the ZIF. The first is that a price level target is associated with a very low neutral rate. The second is that the central bank is assumed to ignore or disregard the implications for the real economy of trying to hit the target price level over too short of a horizon. ${ }^{18}$

Under the same circumstances, could an appropriately designed PLPT rule do better? The answer is certainly yes. Figure 2 reconsiders the above experiment under two alternative assumptions. First, the central bank now follows a PLPT rule where the annual slope of the price level path has been set to 2.5 percent. Second, the PLPT rule has been calibrated to avoid the undesirable consequences of an over-aggressive stance when the central bank attempts to close the price level gap too quickly: this simulation assumes a coefficient of 0.5 on the price level gap in the monetary reaction function.

The higher slope for the price level path, relative to the case of a PLT rule, raises the neutral policy rate by 2.5 percentage points and creates a significant buffer that allows rates to decline without hitting the ZIF. Note that the PLPT rule still requires a significant increase in interest rates in the short run. Also, as inflation declines, the interest rate still undershoots the neutral rate. But the contraction in real activity is now much less severe than it was in the previous case.

With regard to the concern that PLPT rules might be less credible than pure IT rules, it is important to emphasize that PLPT rules would only be used as a guideline for communicating current and future policy actions, just like IT rules are currently used to help construct and publish forecasts in countries that have adopted IT regimes. As is the case in the latter regimes, the current stance of monetary policy is based on a plan for bringing inflation back to target gradually, and in a manner that is cognizant of the implications for the real side of the economy. Under a PLPT rule the central bank's forecast for inflation would continue to represent an ideal intermediate target that is based on available information, and would need to be updated in a timely manner in response to new information.

The only significant difference between a PLPT rule and a pure IT rule is that it would generally take longer for the central bank's forecast for inflation to be equal its long-run target rate, as periods of above average inflation would have to be offset by periods of below-average inflation to return the price level back towards its target path. It is difficult to argue that such a rule would be less credible than simple inflation-targeting rules, as an important prerequisite for a policy rule to be credible is that it has to be robust to different environments. We take as self-evident that pure inflation-targeting rules, which by their very nature have to be abandoned when the ZIF binds, can never be as credible as an appropriately designed PLPT rule. Arguably, this point is even stronger in open economies.

\footnotetext{
${ }^{18}$ Similar considerations hold in the case of inflation-targeting regimes. Critics have argued that IT could result in excessive variability in the real economy if central banks were committed to bringing inflation back to target without concern for real objectives. In practice, central banks that have adopted IT regimes have clearly recognized that, due to lags in the monetary transmission mechanism, it is not possible nor desirable to hit the target at each point in time.
} 
As Svensson (2001) and others have pointed out, monetary authorities can always build anti-deflationary credibility by depreciating the exchange rate sufficiently to generate the expectation of a higher price level in the future.

\section{Some illustrative scenarios}

In what follows, we consider a baseline and three illustrative scenarios to show the implications of the ZIF in the presence of shocks that require easing monetary conditions. We achieve this by simulating the economy's responses to such shocks when the ZIF is binding, and by comparing them with similar responses when the ZIF is not binding.

The 'base case' aims to replicate a number of economic conditions in the recent past of Japan, including low productivity growth and deflation. This baseline scenario is assumed to be the result of both low levels of domestic demand and a medium-term trend productivity growth that is below the long-term steady-state growth rate. More precisely, it is assumed that over some period of time (two decades) $Z_{T}^{H}$ and $Z_{N}^{H}$ fall so that productivity grows a full 1 percentage point below the steady-state growth rate of 2 percent. Note that this steady-state rate represents the growth rate of GDP in the long run as the analysis abstracts from population growth.

The first scenario envisages a negative shock to domestic demand. The second and third scenarios consider shocks to supply that raise the underlying rate of productivity growth in the tradables sector and the nontradables sector, respectively. These two scenarios allow for an analysis of the implications of shocks to real exchange rates and the dynamics of macro adjustments along the lines of Balassa (1964) and Samuelson (1964). ${ }^{19}$ Before we proceed, it is worth emphasizing that our scenarios are purely illustrative and designed to illustrate the major mechanisms at work, as well as the key substantive issues involved with the ZIF. Needless to say, they are not intended to provide a plausible baseline forecast - nor to underscore policy recommendations — for the Japanese economy.

\subsection{An illustrative baseline with binding ZIF and temporary defla- tion}

The solid lines in Figure 3 illustrate our baseline scenario over a time horizon of ten years (40 quarters) for the following variables: GDP growth, the price level and its target path, CPI inflation, nominal and real exchange rate, nominal and real interest rates, GDP growth in the rest of the world, the trade balance, and the current account balance. In the baseline scenario of Figure 3 the ZIF is assumed to be binding for the first seven quarters. In the short run, there is deflation - the combination of falling prices and low growth - but over the medium term the economy recovers and inflation expectations increase.

As indicated earlier, recovery from the ZIF is ensured by assuming that monetary policy is committed to following a rule where interest rates are adjusted to move the price level gradually toward a fixed price level path that rises at the rate of 0.5 percent per annum. Expectations of higher inflation - which result in a reduction of the real interest rate combined with a weaker yen raise aggregate demand and boost actual inflation. Growth

\footnotetext{
${ }^{19}$ The conditions for the Balassa-Samuelson effect in the model depend on the combination of parameter values for the degree of home bias in consumption preferences, the elasticities of substitution between domestically-produced tradables and importables, as well as the elasticities of substitution between nontraded and traded goods.
} 
stabilizes at a rate that remains below its steady-state level for some time beyond the simulation horizon.

In the baseline scenario, the trade and current account are in surplus in the short run, in deficit over the medium term (after about 5 years), and in balance in the steady state. The short-run surplus results from lower demand and slower productivity growth. The mediumterm deficit reflects the positive income effects that short-run surpluses have engendered, boosting domestic demand, and hence helping to ensure that in the steady state the desired net asset position returns to zero (the latter is a simplifying assumption that plays no role in our analysis).

As productivity growth remains below its steady-state rate in both sectors, the real exchange rate appreciates over time. To understand this point, observe that in our model the Balassa-Samuelson effect is operational: an increase in productivity in the tradables (nontradables) sector results in a permanent appreciation (depreciation) of the real exchange rate. Because the size of the nontraded sector is larger than the size of the traded goods sector, an equal increase in productivity in both sectors will result a permanent depreciation. The baseline assumes that productivity growth is lower than the steady-state rate of growth for two decades, representing a large negative shock in both sectors spread over a long period of time which strengthens the real exchange rate. The nominal exchange rate also appreciates over time but at an even faster rate than the real exchange rate, because of the assumptions of implicit long-term inflation objectives of 0.5 percent in Japan and 2.5 percent in the rest of the world.

\subsection{Responses to a negative shock to domestic demand}

The dashed lines in Figure 3 are based on an alternative scenario in which domestic demand turns out to be weaker than in the baseline case. This new scenario is generated by assuming that negative shocks to $Z_{U}^{H}$ and $Z_{I}^{H}$ further reduce consumption and investment spending. In this scenario, the ZIF binds for four additional quarters and the deflationary spiral is more severe with significantly slower growth in the short run. As was the case in the baseline scenario, this spiral is held in check by an eventual increase in inflation expectations as agents recognize that the monetary authorities are prepared to provide the necessary accommodation to return the price level gradually back to target.

Real interest rates rise significantly in the short run, but then start to fall dramatically in anticipation of future increases in the price level even before the ZIF is no longer binding. The scenario shows the potential benefits of targeting an upward-sloping path for the price level instead of a fixed long-term inflation rate: in fact, the latter would result in an unstable deflationary spiral. Note that under the scenario presented in Figure 3 the short-run spillovers to the rest of the world are negative, albeit they are relatively small and short-lived.

Figure 4 considers exactly the same shocks that were used to generate the two scenarios discussed above. However, now we study the counterfactual implications of letting interest rates fall (paradoxically) below zero. Needless to say, these simulations do not represent a potential 'case' for negative interest rates in the real world, but simply allow us to study the direct implications of an economy where the ZIF binds relative to an economy where it does not. In fact, the results without binding ZIF are far less startling than with binding ZIF, as the reduction in nominal interest rates in the short run results in faster declines in real interest rate and makes the downturn in the economy much shorter-lived (Figure 4).

The scenarios above might be interpreted as simply showing the benefits of choosing a 
high enough inflation target that is explicitly designed to avoid the ZIF from binding. They actually go well beyond that, by demonstrating the equilibrating properties of monetary policy rules that embody PLPT. For example, in a fully-stochastic setting it is impossible to rule out hitting the ZIF with pure inflation-targeting rules, even if the inflation target is set as high as 2.0 percent - see Hunt and Laxton (2003). Since a monetary policy rule that embodies PLPT will result in larger and more persistent declines in interest rates in response to deflationary shocks than a pure inflation-targeting rule, such a rule explicitly takes the potential deleterious implications of the ZIF into account, and in practice it works in the direction of reducing the probability of actually hitting the ZIF.

Figure 4 also debunks a common 'strawman' argument against PLPT, which is that pursuing such rules in normal times would result in excessive variability in the business cycle in the presence of significant structural inflation persistence. Such arguments are usually based on the assumption that the slope of the price-level target path is zero, or are based on unrealistic assumptions about the degree of structural inflation persistence in the economy. As can be seen in Figure 4, as long as PLPT rules are realistically designed substantially, in order to bring the price level back to target very gradually - they should not be expected to have harmful effects on cyclical variability in normal times when there is a small risk that the ZIF will become binding. ${ }^{20}$

To conclude this section, it is worthwhile to focus briefly on the implications of openness. Figure 5 reconsiders the same scenarios as in Figure 3, but now the degree of openness in the world economy is twice as large as the base case. ${ }^{21}$ Comparing Figure 5 with Figure 3 suggests that a more open economy is less vulnerable to the problems associated with the ZIF, in the sense that the same negative demand shock results in hitting the ZIF for a much shorter period of time, and with less harmful effects, relative to our base case. In the case with more openness the negative demand shock causes the real exchange rate to depreciate in the short run, while it leads to an appreciation on impact under low openness. In both cases deflation results in very high real interest rates in the short run. With relatively low openness the real interest rate rise is persistent enough to strengthen the home currency in real terms: real interest rates actually increase for one year after the shock. But in a regime of high openness real interest rates are not expected to increase or even remain at a high level for a long time: in fact they start falling immediately after the shock, and the real exchange rate depreciates on impact. These results help explain why a model with a very low degree of openness can become unstable, as a result of the change in the sign of the real exchange rate response.

\subsection{Responses to positive supply shocks}

The solid lines in Figure 6 reproduce the same baseline scenario discussed earlier in Figure 3 , but the dashed lines now illustrate an alternative scenario in which higher productivity growth in the tradables sector is added to the baseline scenario, possibly reflecting the

\footnotetext{
${ }^{20}$ Most inflation-targeting central banks usually choose a target significantly above zero partly because of measurement problems, but also because of concerns that too low a target runs the risk of periodically hitting the ZIF in response to shocks. In fact, most inflation-targeting countries typically choose a target such as 2.0 percent or 2.5 percent, which is significantly higher than what measurement bias alone would suggest - see Batini, Kuttner and Laxton (2005). Using stochastic simulations, Hunt and Laxton (2003) argue that for countries with significant nominal and real rigidities even an inflation target as high as 2 percent may be too low, because such targets combined with conventional monetary policy rules that ignore price-level considerations do not completely rule out hitting the ZIF.

${ }^{21}$ This is achieved by doubling the $\nu_{A}^{H}, \nu_{E}^{H}, \nu_{A}^{F}$ and $\nu_{E}^{F}$ coefficients relative to the baseline calibration.
} 
outcome of structural transformations in the labor and product markets. Figure 7 simply repeats the analysis with the same shocks, but once again in this case interest rates are allowed to fall below zero. In these scenarios an increase in productivity in the tradables sector results in an appreciation in both the short run and the long run.

As was the case for the negative demand shocks earlier, the appropriate policy response is to reduce nominal interest rates relative to the baseline scenario whenever possible (either now if the ZIF is not binding, or in the future if it is binding). The rationale, however, is different. In the earlier scenario of negative demand shocks, a commitment to easing monetary conditions prevented demand from falling further and ensured the injection of sufficient nominal stimulus to stop an ongoing deflationary spiral. In the scenarios of Figures 6 and 7, instead, the positive supply shock actually raises output. However, if the economy starts at the ZIF, supply shocks can extend the period of time over which the ZIF remains binding. In our particular example it extends the period of time the ZIF binds by 2 quarters.

Prima facie comparison of Figures 6 and 7 might suggest that there are only minor complications associated with hitting the ZIF for a longer period of time, as there are small differences between the profiles for real activity and inflation when the ZIF binds and when it does not. Unfortunately, this type of inference derived from deterministic simulation scenarios underestimates the potential complications of supply shocks in the real world, as it implicitly assumes that no further demand or supply shocks would occur in the future. There could be instances where an economy, which is expected to remain for some time at the ZIF as growth-enhancing structural reforms proceed, were to be hit by a new series of negative aggregate demand shocks. In this case the effects of these new shocks would be amplified because they would be 'layered' upon a scenario in which the ZIF was already binding.

To analyze the implications of supply shocks that are concentrated in the nontradables sector, we repeat the above analysis under the assumption that the productivity growth shock is concentrated in the $N$ sector of our model — see Figures 8 and 9. A similar story emerges. The appropriate policy response is to reduce interest rates when it is possible (either now or in the future), and in the case where the ZIF is binding it binds for longer. However, in this case because the shock is concentrated in the nontradables sector it results in a depreciation of the real exchange rate and stronger growth in the short run. As a consequence, when the ZIF is not binding interest rates decline in the short run, but then rise after 2 years to contain the ensuing inflationary pressures stemming from the depreciation of the currency. In this case, the ZIF binds for only one additional quarter relative to the baseline, compared with two quarters when the productivity shock was concentrated in the tradables sector.

\subsection{Raising the inflation target to 2.5 percent}

The simulations reported earlier highlight the potential benefits of moving the economy away from the ZIF as quickly as possible, once the economy hits it. ${ }^{22}$ Figures 10 and 11 illustrate the implications of increasing the slope of the price level target path in the baseline from 0.5 percent to 2.5 percent, per annum.

Figure 10 considers the case where the ZIF is binding initially. In this case, if such a policy were perceived to be credible, it would result in an increase of inflation expectations

\footnotetext{
${ }^{22} \mathrm{~A}$ growing empirical literature shows that central banks in inflation-targeting countries have had significant success in anchoring long-term inflation expectations to their targets - see in particular Levin, Natalucci and Piger (2004), Batini, Kuttner and Laxton (2005), Gürkaynak, Sack, and Swanson (2005).
} 
in the short run, and the period of time over which the ZIF is expected to be binding would shrink. In this particular example, the home country economy is at the ZIF for 4 quarters instead of the 7 quarters in the baseline scenario. Figure 11 reports the case where the ZIF is not binding. Interest rates decline in the short run, providing the reduction in real interest rates needed to stimulate aggregate demand. This increases inflation gradually to its new permanently higher level.

It is sometimes argued that, in practice, it may be difficult to implement such a policy when the ZIF is binding, because the lower real interest rates which are required to stimulate aggregate demand in the short run work entirely through an expectational channel, and by definition cannot be backed up in terms of a reduction in nominal short-term interest rates. However, this argument assumes that the central bank will not take other measures to ensure the credibility of the policy strategy. This assumption seems highly unrealistic. Eggertsson and Woodford $(2003,2004)$ highlight that both monetary and fiscal authorities face a large menu of actions, including the purchase of government securities and real estate assets, to guarantee their commitment to achieving higher price levels in the future. And, as already mentioned, in the context of an open economy it is always possible to engineer sufficient exchange rate depreciation to generate credible expectations of a higher price level in the future.

\section{Conclusion}

Using a two-country simulation model calibrated to the Japanese economy, this paper has carried out a scenario analysis to illustrate possible difficulties in dealing with both demand and supply shocks when the ZIF is binding. The key results concerning the implications of openness on the effectiveness of monetary rules in a deflationary environment have been highlighted at length and need not be rehashed here. Instead, we conclude by commenting briefly on a few directions for further research.

The basic insight of the large body of literature on policy rules is that it is not essential to derive optimal rules based on specific models or views about the economy, but rather to search for rules that are robust across different environments and circumstances. The arguments in the paper, which are based on illustrative scenarios, suggest that PLPT rules should be expected to have significant advantages over either pure IT rules or pure PLT rules (to some extent, PLPT rules combine the best from both IT and PLT approaches). The obvious extension would be to evaluate alternative rules in a fully stochastic environment and, in fact, doing so would likely strengthen the benefits of PLPT rules over their alternatives.

For example, the analysis has ignored the permanent welfare consequences and deadweight losses that would be associated with rules that periodically allow for the occurrence of long deflationary spirals. Also, relative to IT rules, our analysis above has abstracted from the possible welfare benefits that PLPT rules could generate, stemming from lower uncertainty about the future price level. While the effects of uncertainty about price level movements has perhaps been overlooked in this literature, it may become a key issue over time as the policy debate focuses on the demographic consequences of population aging. 


\section{References}

[1] Balassa B., 1964, "The Purchasing Power Doctrine: A Reappraisal," Journal of Political Economy, Vol. 72, pp. 585-596.

[2] Batini, N., K. Kuttner, and D. Laxton, 2005, "Does Inflation Targeting Work in Emerging Markets?", World Economic Outlook, Chapter IV, 161-86.

[3] Batini, N., P. N'Diaye, and A. Rebucci, "The Domestic and Global Impact of Japan's Policies for Growth," IMF Working Paper No. 05/209.

[4] Bayoumi, T., D. Laxton, and P. Pesenti, 2004, "Benefits and Spillovers of Greater Competition in Europe: A Macroeconomic Assessment", NBER Working Paper No. 10416 .

[5] Callen, T., and J. D. Ostry, 2003, Japan's Lost Decade, Policies for Economic Revival, Washington: International Monetary Fund, pp.179-205.

[6] Christiano L., M. Eichenbaum, C. Evans, 1999, "Monetary Policy Shocks: What Have We Learned and To What End?," in Taylor,J., Woodford, M., eds., Handbook of Macroeconomics, Vol. 1A, Amsterdam: North Holland, pp. 65-148.

[7] Eggertsson, G., and M. Woodford, 2003, "Optimal Monetary Policy in a Liquidity Trap," International Workshop on Overcoming Deflation and Revitalizing the Japanese Economy (August)

[8] Eggertsson, G., and M. Woodford, 2004, "Optimal Monetary and Fiscal Policy in a Liquidity Trap," NBER International Seminar on Macroeconomics (July).

[9] Faruqee, H., D. Laxton, D. Muir and P. Pesenti, 2006, "Smooth Landing or Crash? Model-based Scenarios of Global Current Account Rebalancing," forthcoming in R. Clarida (ed.), G7 Current Account Imbalances: Sustainability and Adjustment, NBER conference volume, Chicago, IL: University of Chicago Press.

[10] Greenwood, J., Z. Hercowitz and G.W. Huffman, 1988, "Investment, Capacity Utilization, and the Real Business Cycle," American Economic Review, Vol. 78(3), pp. $402-17$.

[11] Gürkaynak, R., B. Sack, and E. Swanson, 2005, "The Sensitivity of Long-Term Interest Rates to Economic News: Evidence and Implications for Macroeconomic Models", American Economic Review, Vol. 95, 425-36.

[12] Hayami, M., 2001, "Opening Speech", Monetary and Economic Studies, Vol.19(S-1), pp. $9-12$

[13] Hayashi, F., and E.C. Prescott, "The 1990's in Japan: A Lost Decade," The Final International Forum of the Collaboration Projects.

[14] Hunt, B., and D. Laxton, 2001, "The Zero Interest Rate Floor (ZIF) and Its Implications for Monetary Policy in Japan," IMF Working Paper 01/186.

[15] Hunt, B. and D. Laxton, 2003, "The Zero-Interest-Rate Floor and Its Implications for Monetary Policy in Japan," in Tim Callen and Jonathan D. Ostry, eds., Japan's Lost Decade, Policies for Economic Revival, Washington: International Monetary Fund, pp.179-205. 
[16] Laxton, D., P. Isard, H. Faruqee, E. Prasad, and B. Turtelboom, 1998, MULTIMOD Mark III: The Core Steady-State Models, IMF Occasional Paper No. 164.

[17] Levin, A., F. Natalucci, and J. Piger, (2004), "The Macroeconomic Effects of Inflation Targeting", Federal Reserve Bank of St. Louis Review, Vol. 86(4), pp. 51-80.

[18] McCallum, B. T., 2000, "Theoretical Analysis Regarding a Zero Lower Bound on Nominal Interest Rates," Journal of Money, Credit and Banking, Vol. 32(4), pp. 870-904, (November).

[19] McCallum, B. T., 2001, "Inflation Targeting and the Liquidity Trap," NBER Working Paper No. 8225.

[20] Samuelson, P. , 1964, "Theoretical Notes on Trade Problems", Review of Economics and Statistics, Vol. 46, pp. 145-154.

[21] Svensson, L.E.O., 2001, "The Zero Bound in an Open Economy: A Foolproof Way of Escaping From a Liquidity Trap," Monetary and Economic Studies, Vol. 19 (February), pp.277-312.

[22] Taylor, J.B., 1993, "Discretion Versus Policy Rules in Practice," Carnegie-Rochester Conference Series on Public Policy, Vol. 39 (December) pp. 195-214. 
Table 1: Steady-State National Accounts in the Baseline Scenario

(Percentage Shares of GDP)

\begin{tabular}{lll}
\hline & $H$ & $F$ \\
\hline & & \\
Private Consumption $C_{S S} / G D P_{S S}$ & 56.97 & 64.86 \\
Forward-looking consumers $C_{F L, S S} / G D P_{S S}$ & 50.18 & 56.12 \\
Liquidity-constrained consumers $C_{L C, S S} / G D P_{S S}$ & 6.80 & 8.74 \\
Private Investment $p_{E, S S} I_{S S} / G D P_{S S}$ & 23.53 & 17.14 \\
Public Expenditure $G_{S S} / G D P_{S S}$ & 19.50 & 18.00 \\
Trade balance $T B A L_{S S} / G D P_{S S}$ & 0.00 & 0.00 \\
Imports $I M_{S S} / G D P_{S S}$ & 11.03 & 1.45 \\
Consumption Goods $p_{M A, S S} M_{A, S S} / G D P_{S S}$ & 7.62 & 0.72 \\
Investment Goods $p_{M E, S S} M_{E, S S} / G D P_{S S}$ & 3.42 & 0.73 \\
Net Foreign Assets $b_{F, R A T, S S}$ & 0.00 & 0.00 \\
Share of World GDP (percent) $s$ & 11.59 & 88.41 \\
\hline
\end{tabular}

Table 2: Households and Firms Parameters

\begin{tabular}{lll}
\hline & $H$ & $F$ \\
\hline Share of liquidity constrained consumers $s_{L C}$ & 0.40 & 0.40 \\
\hline Annualized rate of time preference $100 *\left(\beta_{S S}^{-4}-1\right)$ & 1.43 & 2.59 \\
Depreciation rate $\delta$ & 0.02 & 0.02 \\
Intertemporal elasticity of substitution $1 / \sigma$ & 5.00 & 5.00 \\
Habit persistence in consumption $b_{c}$ & 0.91 & 0.91 \\
Inverse of the Frisch elasticity of labor $\varsigma$ & 2.50 & 2.50 \\
Habit persistence in labor $b_{\ell}$ & 0.75 & 0.75 \\
\hline Tradable Intermediate Goods & & \\
\hline Substitution between factors of production $\xi_{T}$ & 0.75 & 0.75 \\
Weight of capital $\alpha_{K T}$ & 0.73 & 0.57 \\
\hline Nontradable Intermediate Goods & & \\
\hline Substitution between factors of production $\xi_{N}$ & 0.75 & 0.75 \\
Weight of capital $\alpha_{K N}$ & .70 & 0.56 \\
\hline Final Consumption Goods & & \\
\hline Substitution between domestic and imported goods $\mu_{A}$ & 2.50 & 2.50 \\
Weight of domestic goods $\nu_{A}$ & 0.59 & 0.97 \\
Substitution between domestic tradables and nontradables $\varepsilon_{A}$ & 0.50 & 0.50 \\
Weight of tradable goods $\gamma_{A}$ & 0.36 & 0.34 \\
\hline Final Investment Goods & & \\
\hline Substitution between domestic and imported goods $\mu_{E}$ & 2.50 & 2.50 \\
Weight of domestic goods $\nu_{E}$ & 0.81 & 0.96 \\
Substitution between domestic tradables and nontradables $\varepsilon_{E}$ & 0.50 & 0.50 \\
Bias towards tradable goods $\gamma_{E}$ & 0.77 & 0.75 \\
\hline
\end{tabular}


Table 3: Price and Wage Markups

\begin{tabular}{lcc}
\hline & $H$ & $F$ \\
\hline $\begin{array}{l}\text { Tradables } \\
\text { Markup } \theta_{T} /\left(\theta_{T}-1\right)\end{array}$ & 1.26 & 1.18 \\
Nontradables & & \\
Markup $\theta_{N} /\left(\theta_{N}-1\right)$ & 1.29 & 1.23 \\
Wages & & \\
Markup $\psi /(\psi-1)$ & 1.20 & 1.20 \\
\hline
\end{tabular}

Table 4: Nominal and Real Rigidities

\begin{tabular}{lll}
\hline & $H$ & $F$ \\
\hline Real Rigidities & & \\
\hline Capital accumulation $\phi_{I 1}$ & 1.00 & 1.00 \\
Investment changes $\phi_{I 2}$ & 78.00 & 78.00 \\
Imports of consumption goods $\phi_{M A}$ & 0.95 & 0.95 \\
Imports of investment goods $\phi_{M E}$ & 0.95 & 0.95 \\
\hline Nominal Rigidities & & \\
\hline Wages of liquidity-constrained consumers $\phi_{W L C}$ & 400 & 400 \\
Wages of forward-looking consumers $\phi_{W F L}$ & 400 & 400 \\
Prices of domestic tradables $\phi_{P Q}$ & 400 & 400 \\
Prices of nontradables $\phi_{P N}$ & 400 & 400 \\
Prices of imports $\phi_{P M}$ & 3200 & 3200 \\
\hline
\end{tabular}

Table 5: Base-Case Monetary Policy Reaction Function Parameters

\begin{tabular}{lcc}
\hline & $H$ & $F$ \\
\hline Inflation gap $\omega_{\pi}$ & 2.0 & 2.0 \\
Price Level gap $\omega_{P}$ & 0.5 & 0.0 \\
\hline
\end{tabular}


Figure 1: Price Level is Initially 5 Percent Higher Than Target With a Zero Slope in the Target Path
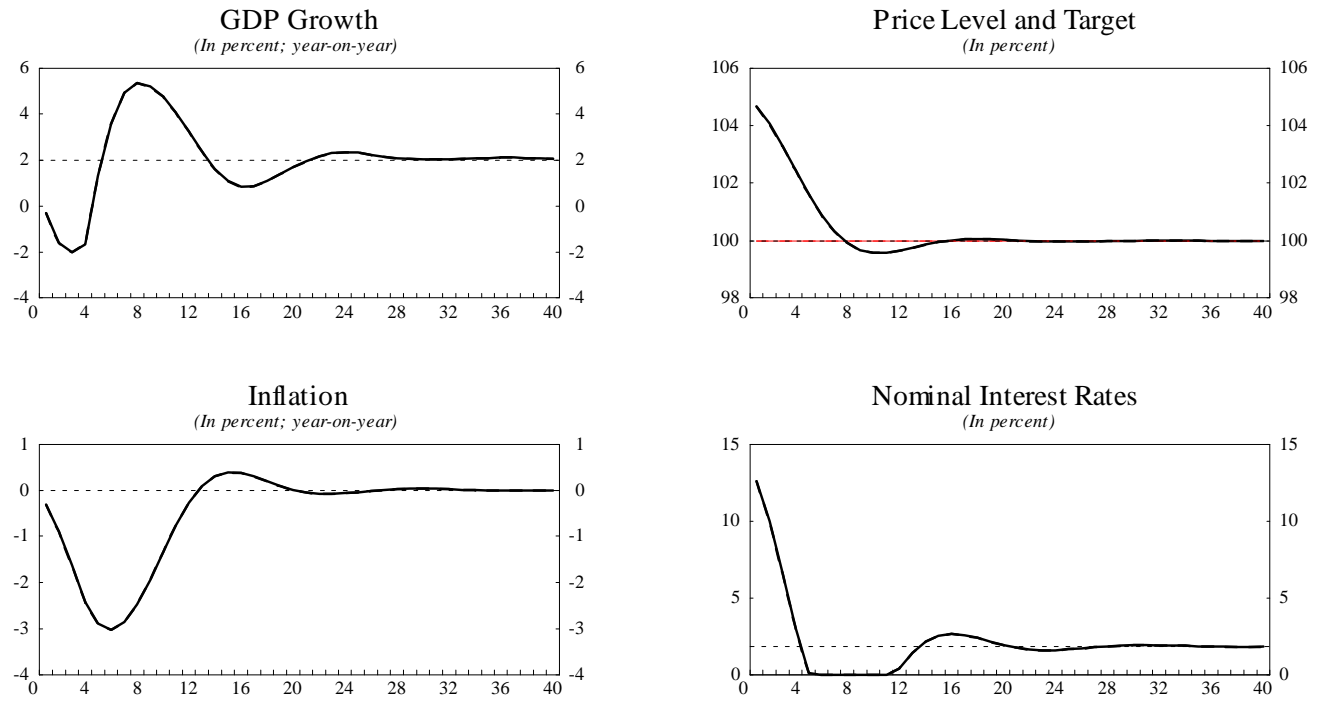
Figure 2: Price Level is Initially 5 Percent Higher Than Target With a $2.5 \%$ Slope in the Target Path
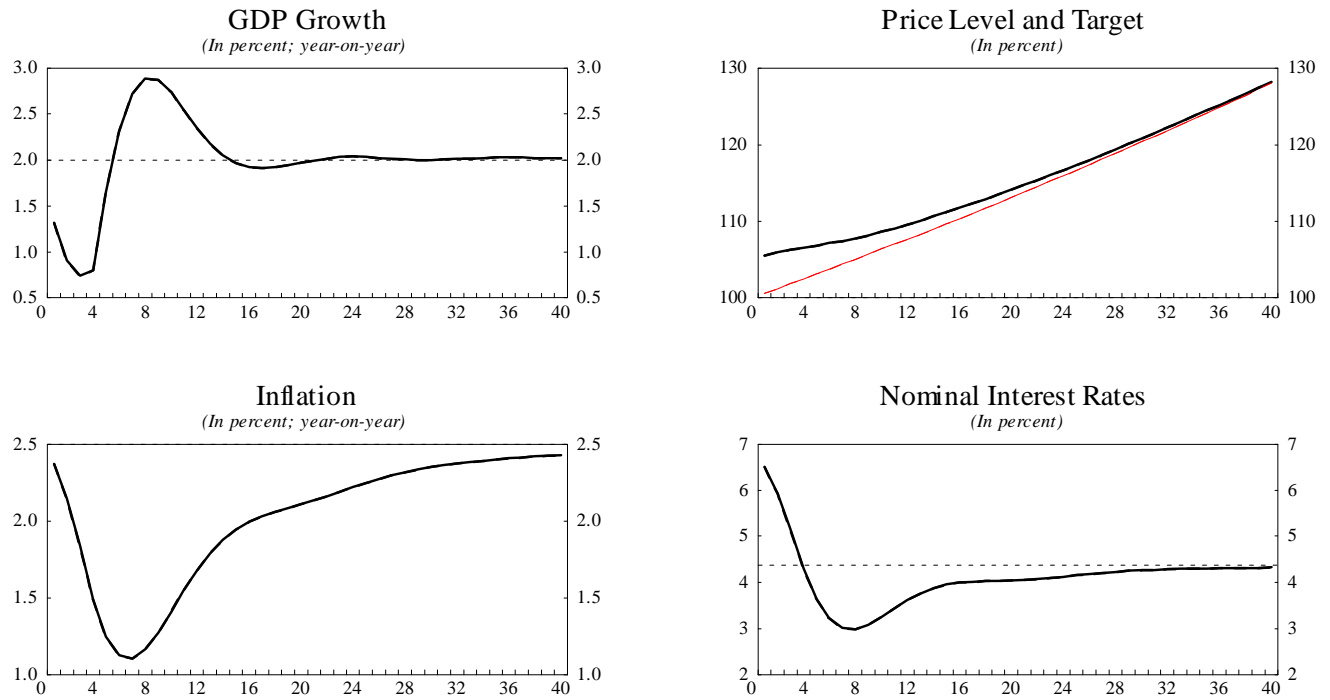
Figure 3: Base Case and Scenario with Negative Demand Shock with ZIF
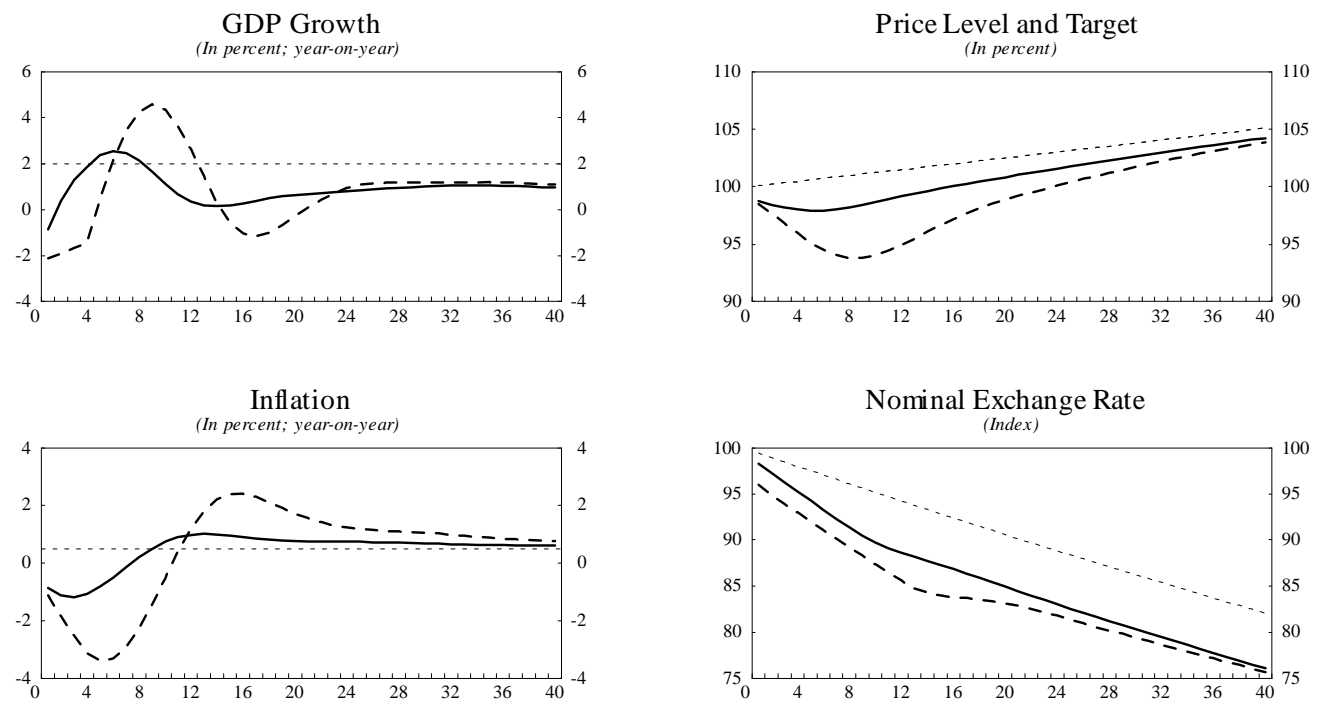

Real Exchange Rate
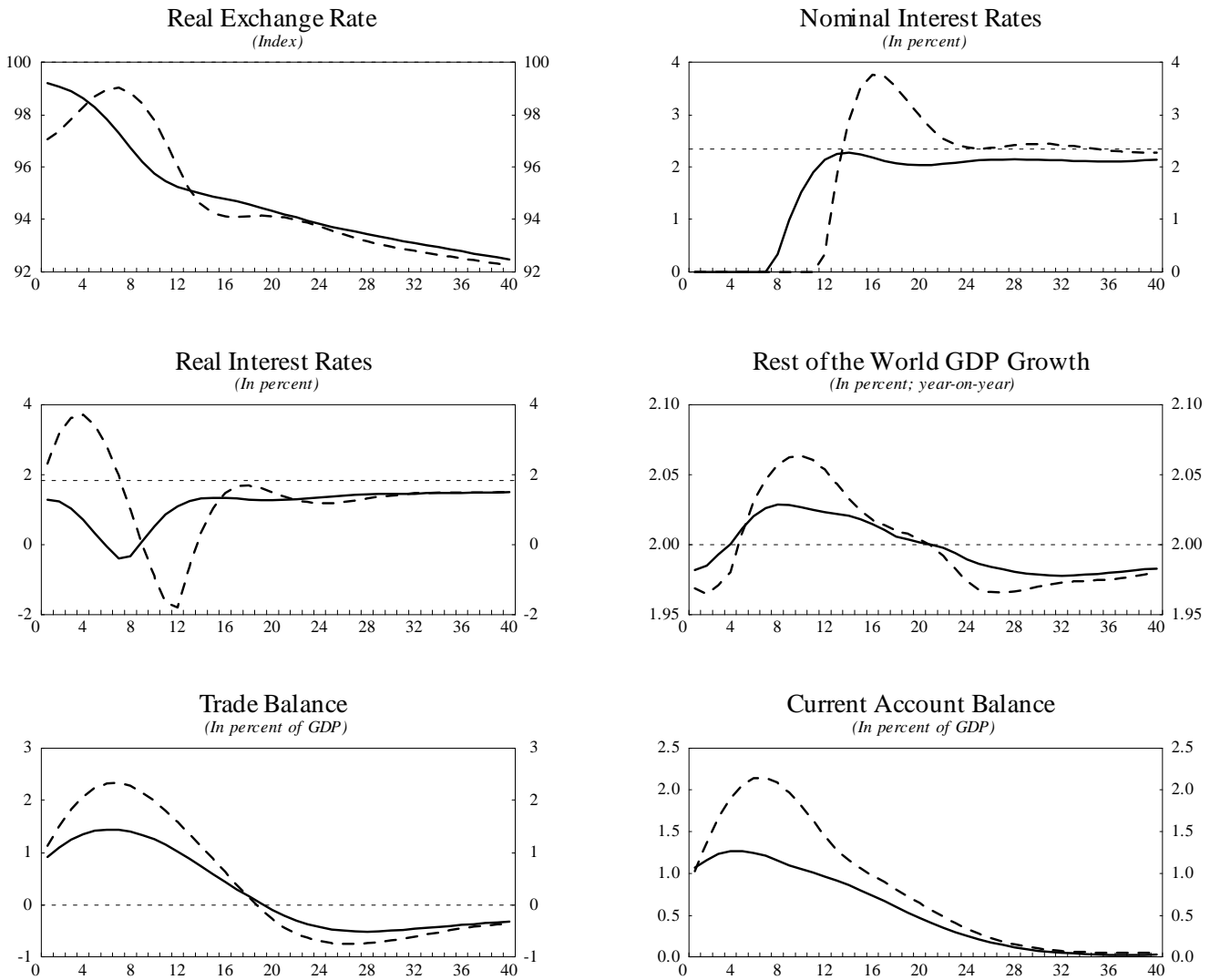
Figure 4: Base Case and Scenario with Negative Demand Shock without ZIF
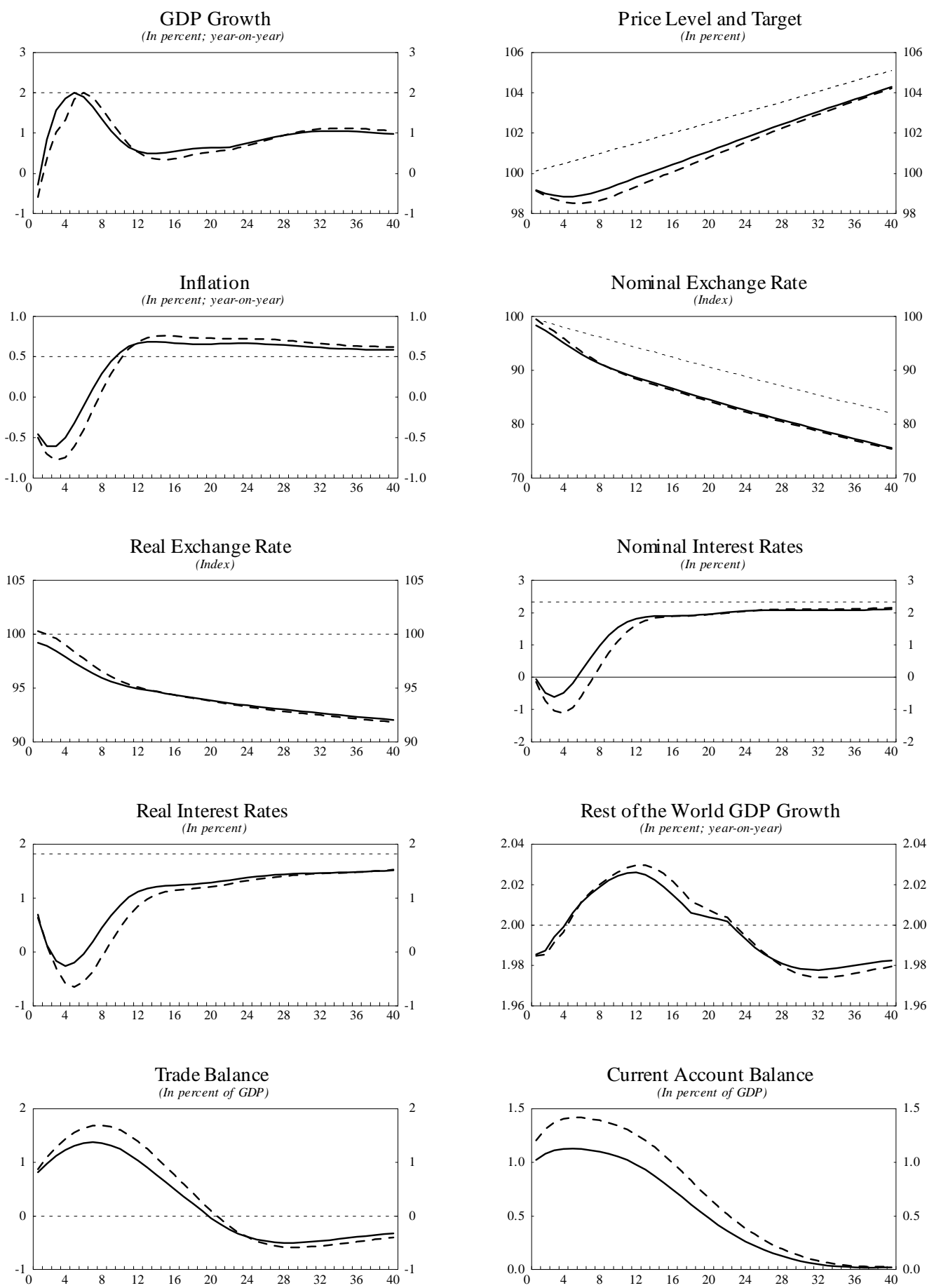
Figure 5: Base Case and Scenario with Negative Demand Shock with ZIF and Double Openness
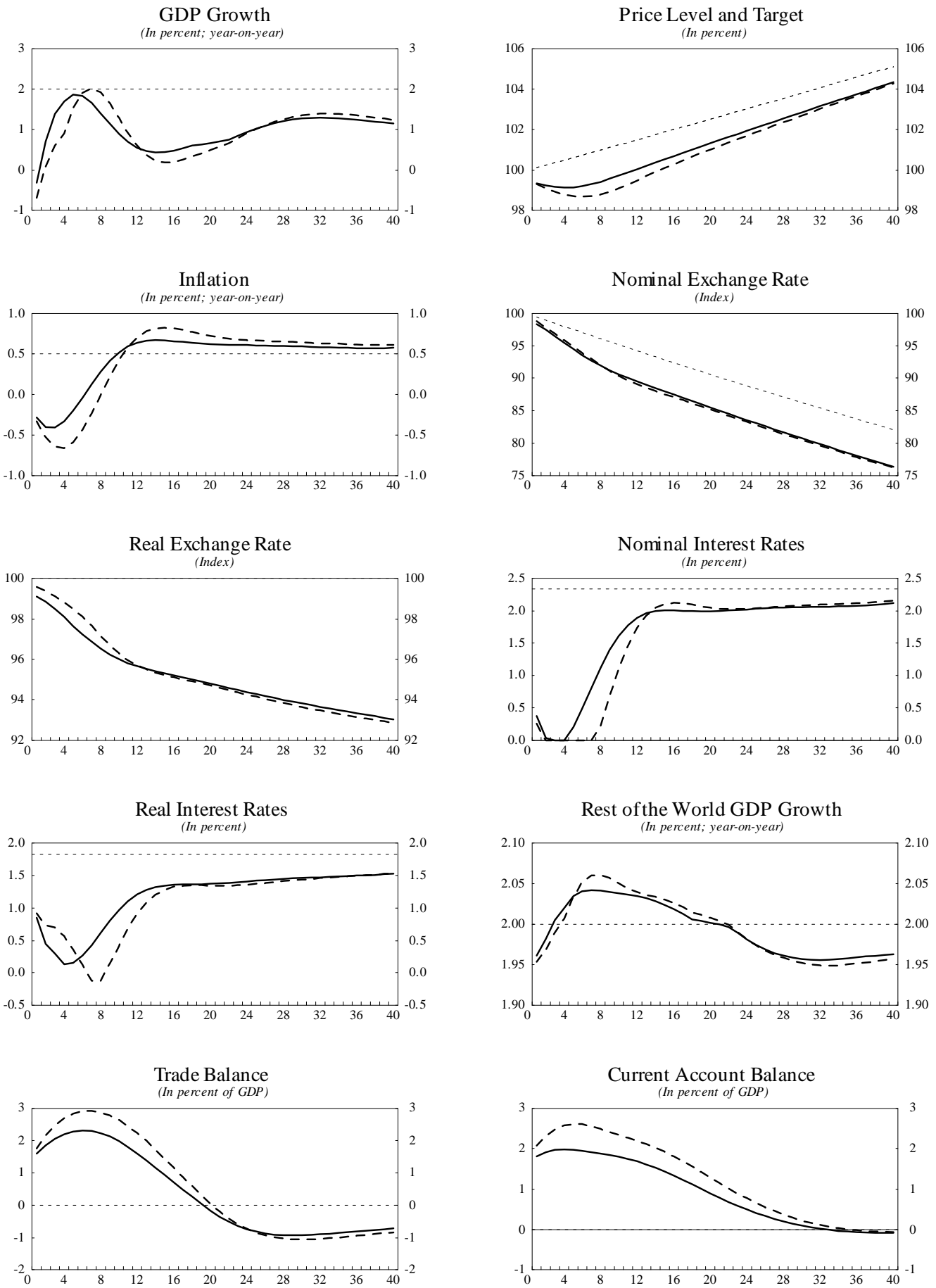
Figure 6: Base Case and Scenario with Productivity Growth Shock in Tradables Sector with ZIF
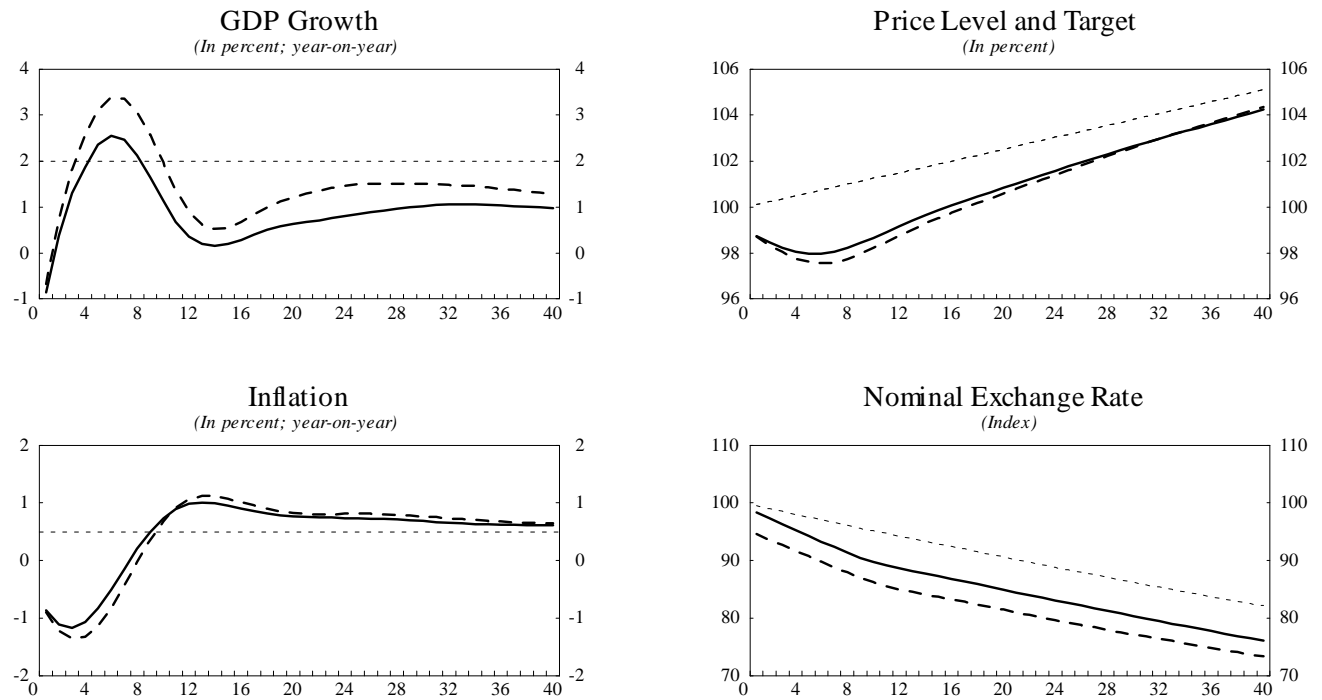

Real Exchange Rate
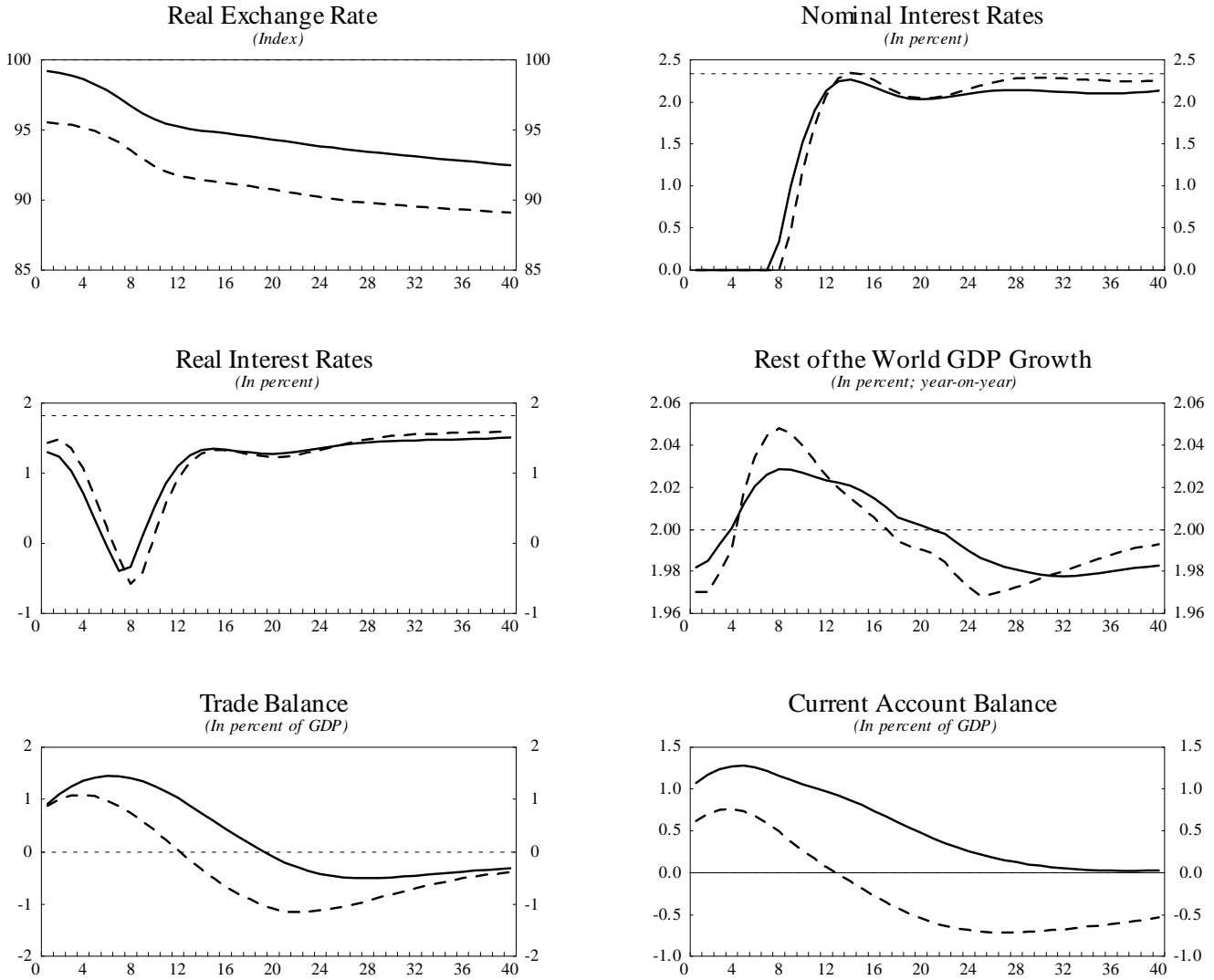
Figure 7: Base Case and Scenario with Productivity Growth Shock in Tradables Sector without ZIF
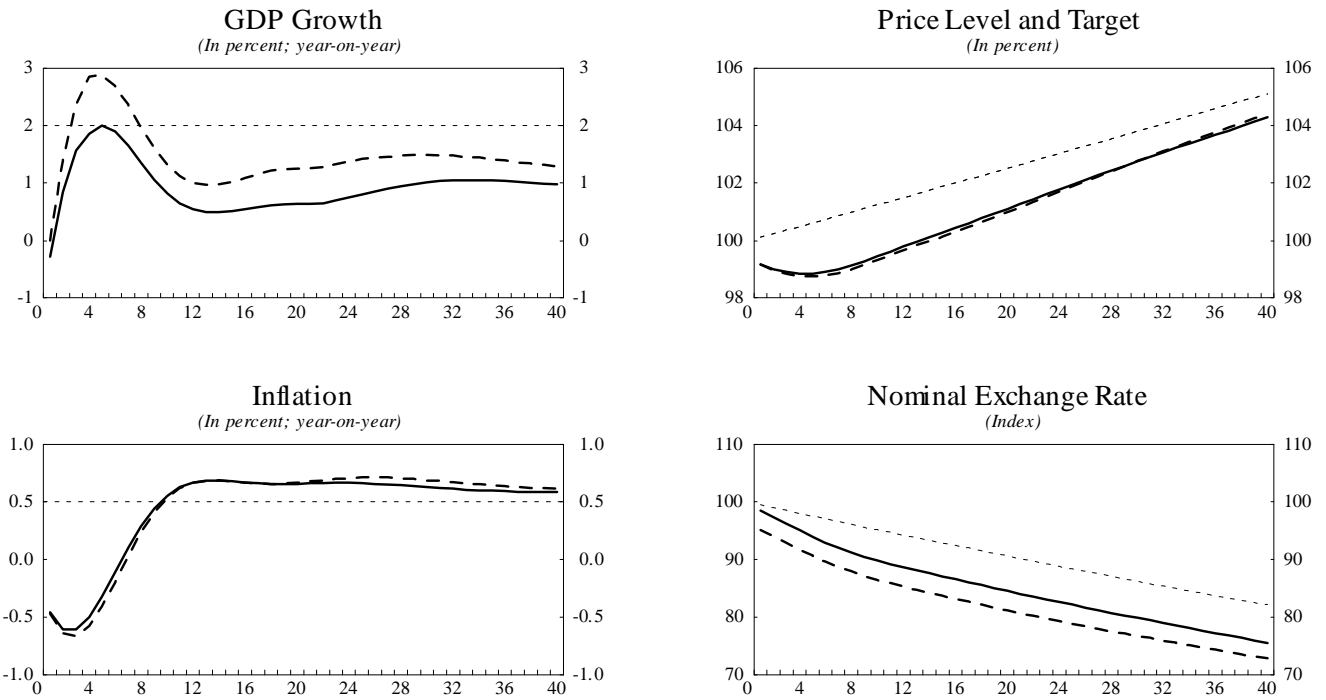

Real Exchange Rate
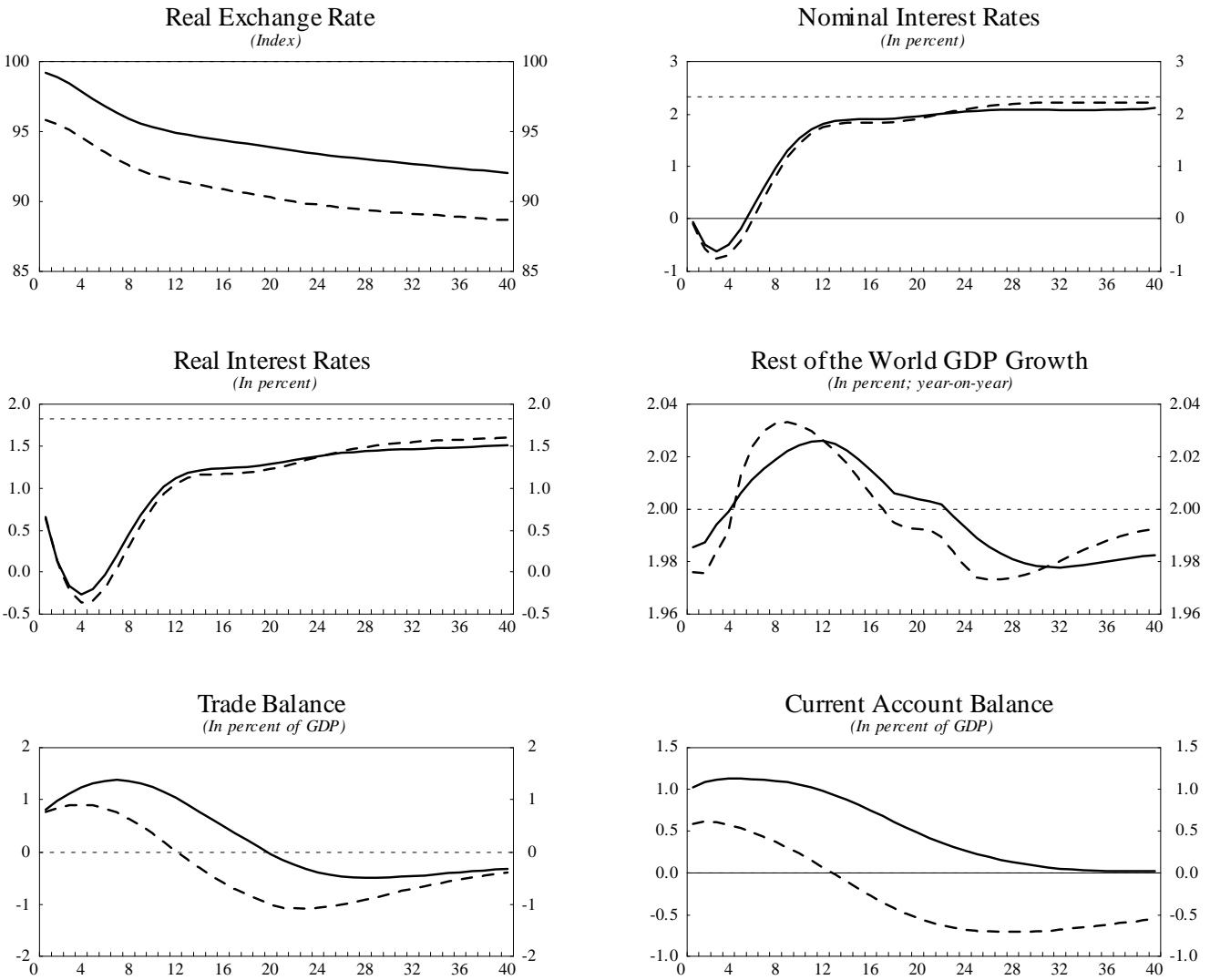
Figure 8: Base Case and Scenario with Productivity Growth Shock in Non-Tradables Sector with ZIF
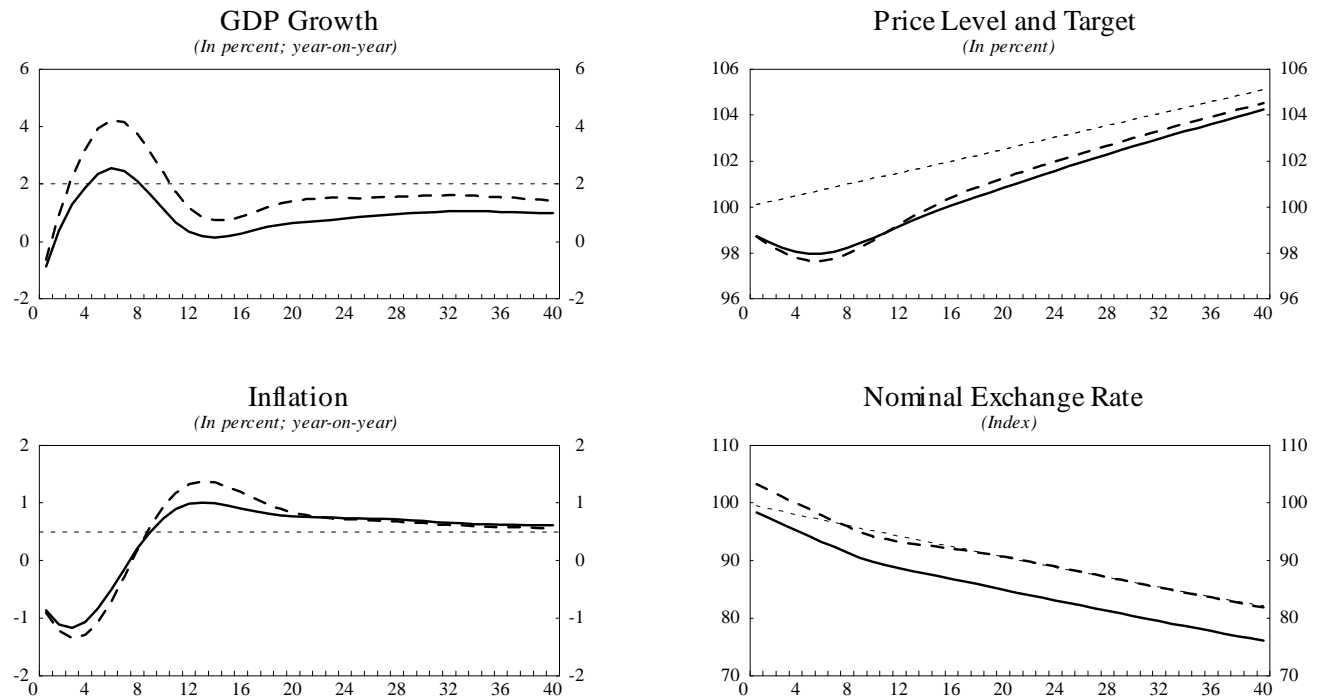

Real Exchange Rate
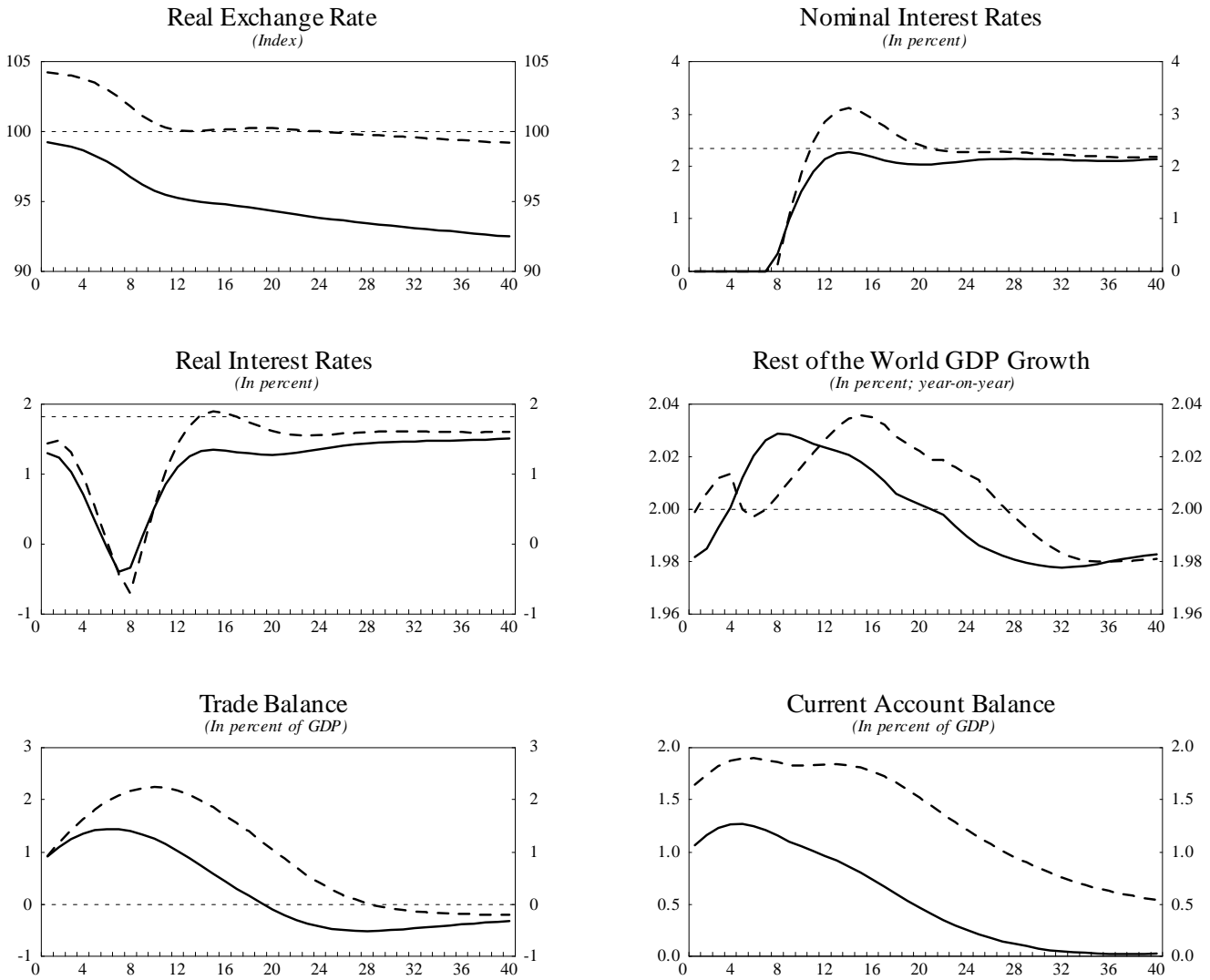
Figure 9: Base Case and Scenario with Productivity Growth Shock in Non-Tradables Sector without ZIF
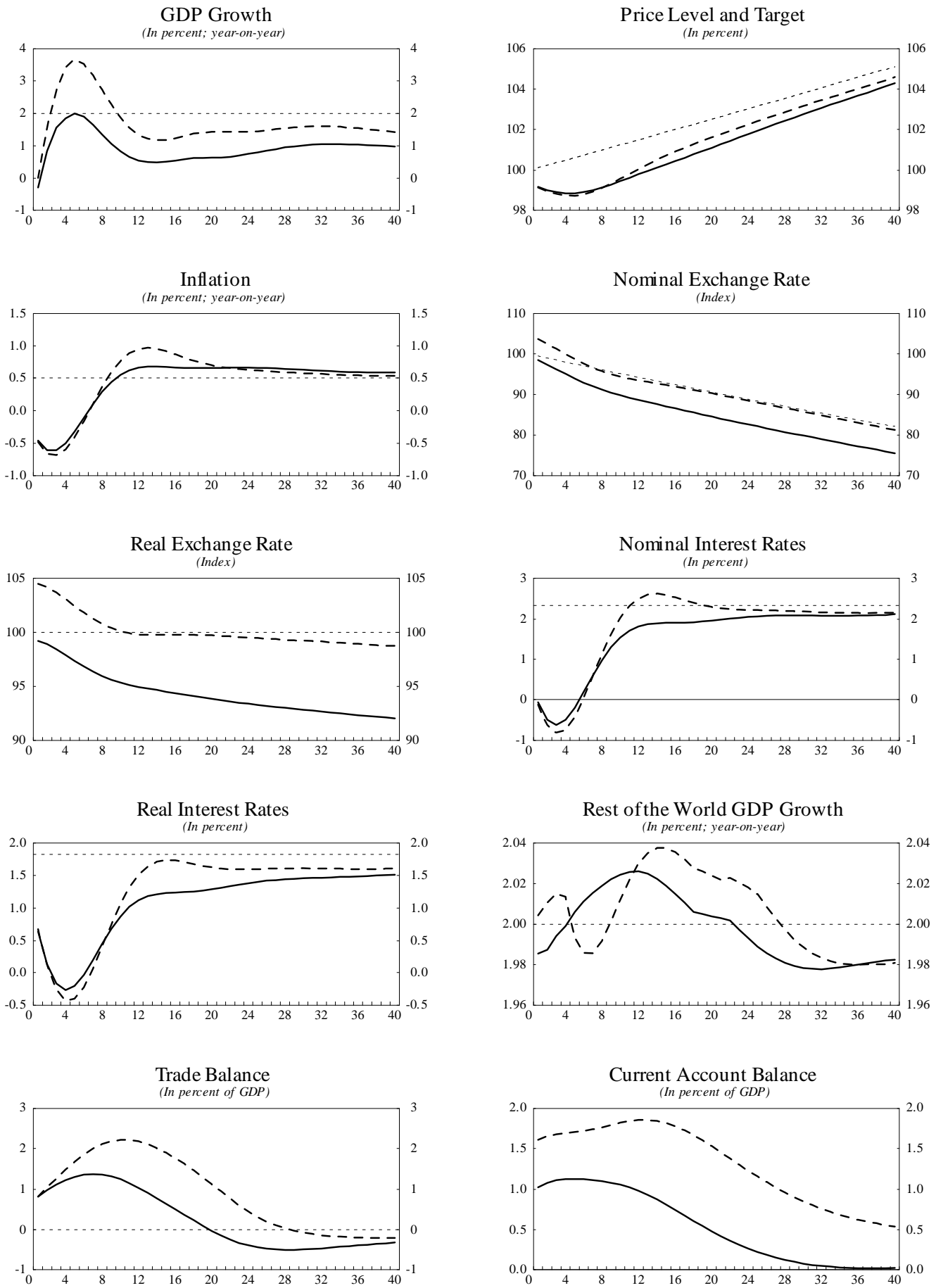
Figure 10: Base Case and New Scenario with an Annual 2.5\% Slope in the Price Level Target Path with ZIF
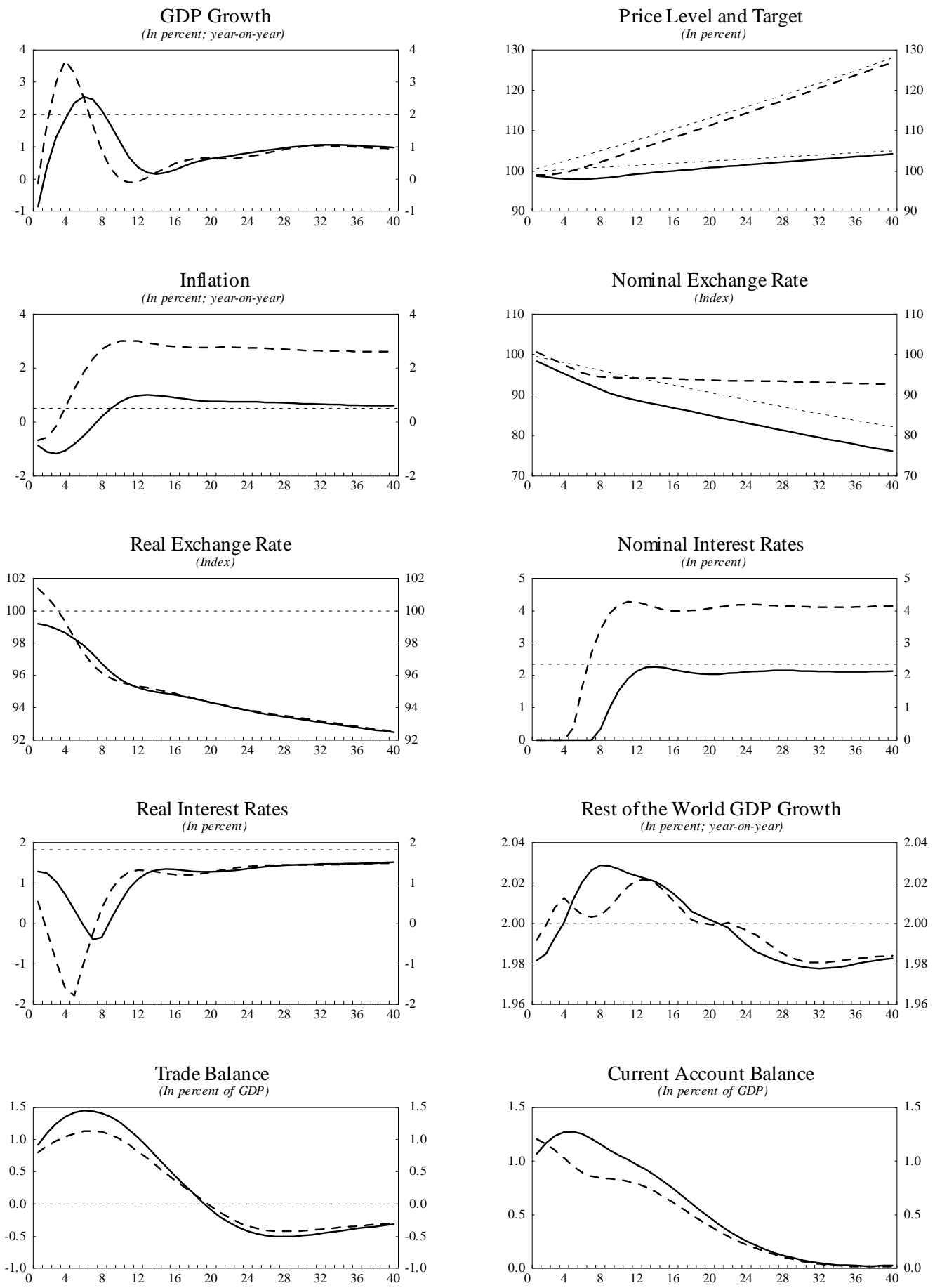
Figure 11: Base Case and New Scenario with an Annual 2.5\% Slope in the Price Level Target Path without ZIF
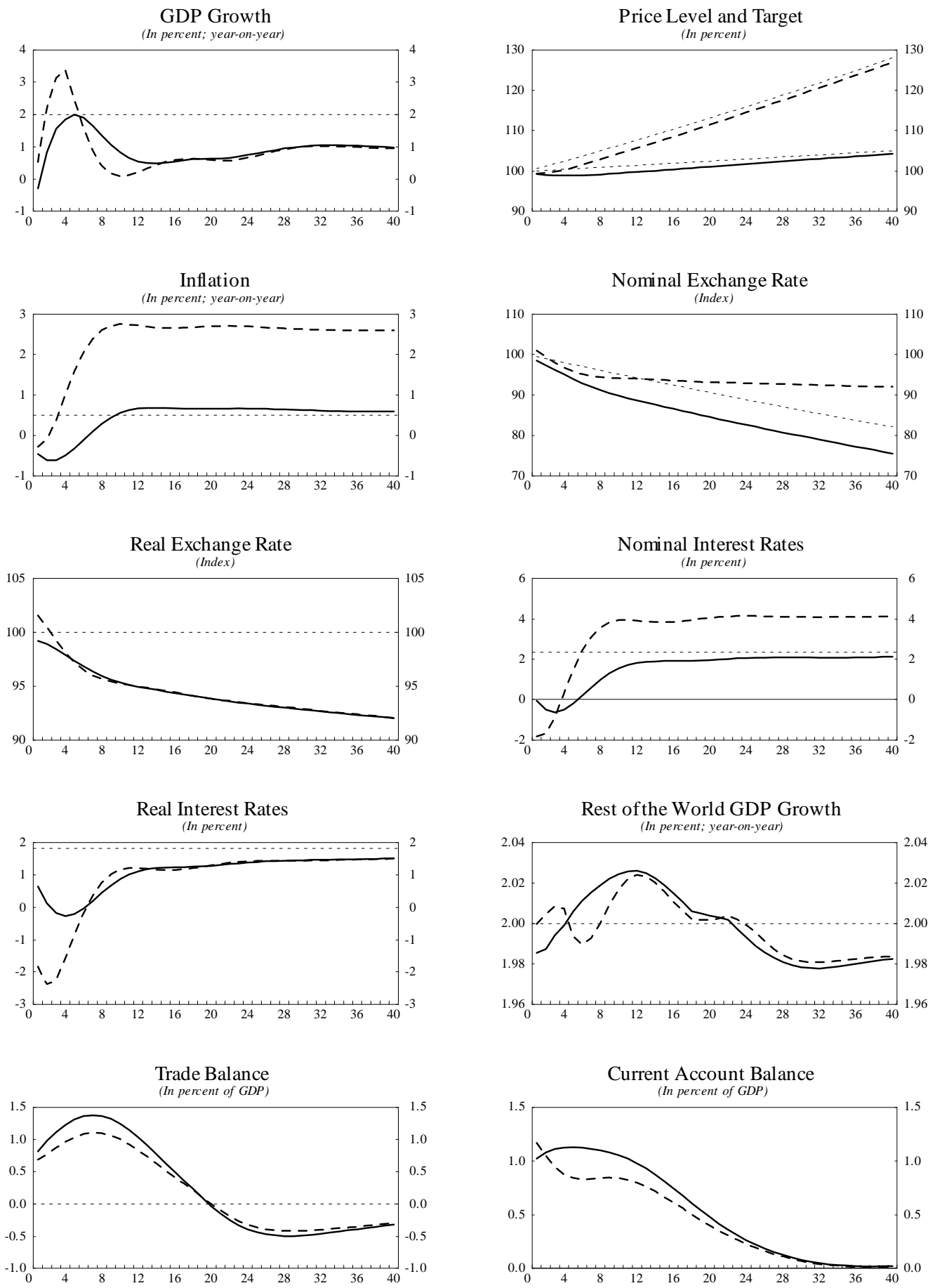